\title{
ESTADO DEL ARTE
}

\section{BIOLOGÍA, PATOBIOLOGÍA Y BIOCLÍNICA DE LA HOMOCISTEÍNA EN LA ESPECIE HUMANA}

Grégory Alfonso García MD*

\section{Resumen}

La homocistinuria fue descrita en 1962 en niños con dificultades de aprendizaje y en 1969 McCully informó la evidencia en autopsias de trombosis arterial extensa y aterosclerosis en niños con elevadas concentraciones de homocisteína plasmática y homocistinuria. La homocisteína, un aminoácido de azufre, es un metabolito intermedio de la metionina, y sobre la base de estos hallazgos bioquímicos, ellos propusieron que la homocisteína plasmática elevada puede causar lesión neural y enfermedad vascular aterosclerótica. Hoy se considera un factor de riesgo independiente para esta última. La hiperhomocistinemia leve es bastante prevalente en la población general. Puede deberse a defectos genéticos en las enzimas que participan en el metabolismo de la homocisteína, carencias nutricionales de vitaminas y cofactores, ciertos medicamentos, ingesta rica en metionina o enfermedad renal. La alta concentración puede reducirse con folato, y es así que la suplementación vitamínica ha sido propuesta en individuos con hiperhomocistinemia con el fin de reducir su riesgo de enfermedad cardiovascular. En este artículo hacemos una revisión de la biología, la patobiología y la bioclínica del metabolismo de la homocisteína.

Palabras clave: enfermedad cardiovascular, errores innatos del metabolismo, hiperhomocistinemia, homocisteína, metionina, hígado.

Abreviaturas: HomCis, homocisteína; HiperHomCis, hiperhomocistinemia; MET, metionina; SAM, S-adenosilmetionina.

\section{Abstract}

Homocystinuria was firstly described in 1962 en children with learning difficulties, and in 1969 McCully reported autopsy evidence of extensive arterial thrombosis and atherosclerosis in children with elevated plasma homocysteine concentrations and homocystinuria. Homocysteine, a sulfur amino acid, is an intermediate metabolite of methionine, and in the both cases mentioned, on the basis of these finding biochemical, they proposed that elevated plasma homocysteine (hyperhomocysteinemia) can cause neural injury and atherosclerotic vascular disease. Hyperhomocysteinemia is now well established as an independent risk factor for atherosclerotic vascular disease. Mild hyperhomocysteinemia is quite prevalent in the general population. It can be caused by genetic defects in the enzymes involved in homocysteine metabolism or nutritional deficiencies in vitamin cofactors, certain medications, high methionie intake or renal disease. The homocysteine concentration can be lowered with folate, and it's so vitamin supplementation has thus been proposed in individuals with hyperhomocysteinemia in order to reduce their cardiovascular disease risk. In this article, we review the biology, pathobiology and bioclinic of the metabolism of homocysteine.

Key words: cardiovascular disease, homocysteine, hyperhomocisteinemia, inborn errors, liver, methionine.

Fecha recibido: agosto 20 de 2009 - Fecha aceptado: febrero 5 de 2010

* Experto Genética, Bioquímica y Biología Celular y Molecular Humana. Docente experto Farmacología y Toxicología Humana. Facultad de Medicina. Unidad de Educación. Unisánitas. Grupo de Medicina
Translacional. Instituto de Investigación. Unisánitas. Laboratorio de Inmunología Clínica. Facultad de Ciencias. Pontificia Universidad Javeriana. Bogotá DC. Colombia.

Concepto visual gráfico y diagramación, Giovanny Alexander Jácome. 


\section{Definiendo el problema de la homocisteína}

La HomCis un aminoácido no proteico (es decir que no participa en la síntesis proteica), que contiene azufre en forma de sulfuro sintetizado a partir de la MET. Ésta deriva su nombre met de la presencia de un grupo metilo $\mathrm{y}$ de tio=thio o thiol que proviene de azufre y dada la presencia de este grupo metilo, juega un rol vital en el llamado "ciclo del átomo de carbono, del 1-carbono o trampa de folato" también denominado "ciclo del pool del átomo de carbono, o ruta o vía de la transmetilación", que consiste en que a través del transporte de metilos y formas homólogas (formilo, formato) en intermediarios moleculares (como la MET) y gracias al papel de las vitaminas B9 (ácido fólico) y B12, se garantiza el aporte de carbono para la síntesis de las cuatro principales biomoléculas: ácidos nucleicos, proteínas, carbohidratos y lípidos. ${ }^{1}$ La HipHomCis ha aparecido en la trama patobiológica de la enfermedad vascular (cardio y cerebrovascular ${ }^{2,3}$ en la génesis de varias afecciones neurológicas, psiquiátricas y neuropsiquiátricas tales como la neurodegeneración y la demencia ${ }^{4}$ en el autismo, ${ }^{4,5}$ la esquizofrenia, ${ }^{4,6}$ la depresión ${ }^{4,6,7}$ en particular en personas de la tercera edad ${ }^{4,6,7,8}$ y en diversos escenarios de las enfermedades gestacionales. ${ }^{9,10}$ Dado lo anterior, es fundamental una aproximación al problema del metabolismo de la HomCis en el ámbito biológico y patobiológico humano.

\section{Metodología, estrategia de búsqueda y fuentes bibliográficas}

El tipo de revisión que vamos a efectuar es narrativa y descriptiva, del tipo revisión de revisiones, o revisión secundaria. Nuestra búsqueda se sustentó en tres campos:

- Los textos clásicos de bioquímica humana reconocidos como Devlin ${ }^{11}$, Lehninger ${ }^{12}$ y Stryer $^{13}$, y el texto clásico de enfermedadas hereditarias y de errores del metabolismo de Scriver. ${ }^{14}$

- Los bancos de genética, genómica, proteómica y enzimología. Se consultó el banco de genética y genómica humana MIM (Mendelian Inheritance McKusick) ${ }^{15}$ el HUGO (Human Genome Organization) ${ }^{16}$ y el IUMBM (International Union of Biochemistry and Molecular Biology). ${ }^{17}$ Se utilizará la nomenclatura y codificación para genes, proteínas y enzimas, asignada por estas tres bases de bioinformática.

- Los bancos de bibliografía científica. Para la búsqueda de bibliografía y literatura científica médica humana, se consultaron los dos principales bancos electrónicos: el norteamericano PUBMEDLINE (National Library of Medicine database $)^{18}$ y el europeo EMBASE (The bibliographic database for biomedical and pharmacological information). ${ }^{19} \mathrm{La}$ matriz de búsqueda que se aplicó para PubMed y EMBASE fue "human (methionine and/or homocysteine and/or hyperhomocysteinemia) review" con los campos "biology, biochemistry, cardiology, diabetes, diabetelogy, endocrinology, hematology, immunobiology, molecular cell biology, immunology, nephrology, neurobiology, neuroscience, pharmacology, pathobiology, pathology, toxicology" con conectores "or, and, or/and", en lengua inglesa, francesa, alemana y española, y con los límites temporales de la literatura publicada y agregada en los últimos tres años. Se seleccionaron las bibliografías más significativas y completas para cada campo y subcampo relacionado. Se tomaron algunas referencias de importancia histórica y bibliográfica previa, para poder soportar algunos aspectos académicos del escrito.

No mencionaremos nada al respecto de farmacoterapéutica, dada la extensión del artículo, y la importancia de ello involucra la necesidad de otra revisión.

\section{Historia}

Ya en 1947 se hablaba de metilación, ${ }^{20}$ pero sólo en 1963 Greenberg fue el primero en mencionar su trascendencia a varios niveles biológicos, ${ }^{21}$ la HomCis fue detectada en sistemas biológicos hacia $1955^{22}$ y Bartosinski B. en 1964 determinaba la biosíntesis del grupo metilo de la MET. ${ }^{23}$ En 1951 en hígados de ratas se encontró la importancia de este órgano en el metabolismo de la 
HomCis ${ }^{24}$ y en 1952 comenzó a determinarse la existencia y biosíntesis de la MET en la bacteria E. coli. ${ }^{25}$ Eger $^{26}$ y Trutschel $^{27}$ en 1957 en la literatura alemana ya hablan del rol de la HomCis, la homocisteína-thiolactona (HCTL), la cisteína y la cistathionina en la enfermedad hepática.

Frimpter en 1961 comenzó el camino de la patología clínica de los trastornos metabólicos de los sulfoaminoácidos, ${ }^{28}$ pero sólo en 1965 la escuela francesa aportó (Freycon \& Freycon) la descripción del desorden denominado homocistinuria ${ }^{29}$ y en 1967 Chatagne ya formalizaba algunos hallazgos bioquímicos comunes en las metabolopatías de los sulfoaminoácidos. ${ }^{30}$ Por su parte Crawhall \& Watts describían la cistinuria ${ }^{31}$ y en 1969 se comienzan a mencionar las alteraciones bioquímicas de la MET y el ácido metilmalónico relacionadas con la vitamina B12. ${ }^{32}$ Hogenkamp en 1968 establecía las reacciones enzimáticas que involucran los cofactores llamados corrinoides, es decir, los derivados de la vitamina B12 $2^{33}$ y Bertino \& Hillcoat lo hacían con los folatos. ${ }^{34}$

En 1958 Sakami \& Stevens comenzaron a describir y estudiar la s-adenosil-metionina (SAM) ${ }^{35}$ y en 1970 Lombardini \& Talalay esclarecían el metabolismo en su totalidad, ${ }^{36}$ mientras Weissbach \& Taylor definían el rol de la vitamina B12 y el ácido fólico en el metabolismo de la MET. ${ }^{37}$ En ese mismo año ya se listaban y estudiaban los defectos hereditarios del metabolismo de la vitamina $\mathrm{B} 12^{38} \mathrm{y}$ cómo fármacos, toxinas y aminoácidos dietarios afectan la absorción y la utilización de la vitamina B12 y el ácido fólico. ${ }^{39}$ Hoffbrand \& Waters comenzaban a entender el rol del metabolismo de la vitamina B12, el ácido fólico y el metabolismo de los sulfoaminoácidos en las anemias megaloblásticas. ${ }^{40}$

\section{Bioquímica de la homocisteína}

La HomCis es una MET sin su grupo metilo porque lo ha transferido o donado, $\mathrm{y}$ en ese orden de ideas desde el punto de vista bioquímico tiene varios destinos.

- La HomCis es un intermediario metabólico en la transferencia de grupos metilos activados desde el tetrahidrofolato a la s-Adenosil-metionina (SAM, SAME, SAMe o AdoMet). La SAM se considera como donador y aceptador universal de metilos, pues- to que puede ser la fuente de metilos en muchas reacciones que necesiten de él. Se biosintetiza a partir de la transferencia de la adenosina estructural del ATP al grupo sulfuro de la MET.

- Puede ser remetilada hacia MET y hacer que la MET sea un intermediario transportador y donador de metilos. En esta reacción un grupo metilo a partir de n-5-metil-tetra-hidrofolato se transfiere a la HomCis por una enzima denominada metionina-sintetasa (n-5-metil-tetra-hidrofolato-homocisteína-metiltransferasa), la cual requiere como coenzima a la metil-cobalamina (mecobalamina o $\mathrm{MeCbl}$ ), un derivado de la vitamina B12. El cofactor metilcobalamina se encuentra en su forma cob(I)alamina y con la biosíntesis de MET es oxidada hacia cob(II)amina, y la enzima queda inactiva. De tal forma que para reactivar la enzima hay que reducir la cobalamina cob(II)alamina a cob(I)amina, reacción catalizada por la enzima metionina-sintetasareductasa, la cual utiliza para esta remetilación reductora SAM y nicotinamida-adenininadinucleótico-fosfato-reducido(NADPH). La estequiometría de la metionina-sintetasa y la metionina-sintetasa-reductasa es $1: 1$, y es más, se ha encontrado que la metionina-sintetasa-reductasa funciona como una chaperonina para la otra enzima.

- Una ruta menor de remetilación utiliza colina dietaria para una reacción catalizada por la betaína:homocisteína-metil-transferasa, enzima limitada al hígado. Para ello la colina se cataliza antes hacia betaína por la enzima colina-deshidrogenasa.

- Entrar a la biosíntesis de cisteína. En esta ruta la SAM se hidroliza por la SAM-hidrolasa liberándose HomCis y adenosina. La HomCis es el sustrato de la enzima vitamina-B6-dependiente cistationina$\beta$-sintetasa, la cual cataliza su condensación con un aminoácido de serina para formar la cistationina que después es clivada por la $\gamma$-cistationasa para formar 2-oxoglutarato (también denominado 2-oxobutirato o $\alpha$-cetobutirato) y cisteína. Esta vía se denomina como ruta de la trans-sulfuración que tiene una distribución limitada siendo identificada sólo en hígado, riñón, intestino delgado y páncreas. El exceso de HomCis tras ser convertida a cisteína es oxidada a 
taurina e incluso de manera eventual a sulfatos inorgánicos.

- Ser liberada al espacio extracelular, llegar al plasma y eliminarse por la orina.

- Una ruta menor en el metabolismo humano es la deaminación.

- Puede activarse hacia homocisteinil-tRNA ${ }^{\mathrm{Met}}$ con la consecuente producción colateral de radicales libres, en especial el intermediario reactivo denominado como "homocisteína-thiolactona", que es un thioéster-cíclico. Esta ruta parece mostrar la inadecuada metilación de homocisteína-tRNA ${ }^{\text {Met }}$ a metionina-tRNA $^{\text {Met }}$. También se ha encontrado que la MET con activación adecuada con su metioniltRNA ${ }^{\text {Met}}$-sintetasa puede sufrir una edición hacia un análogo de la homocisteinil-thiolactona denominado como s-metionil-homocisteína-thiolactona (SMHT). La SMHT puede ser un donador menor de metilos o ser hidrolizado hacia MET. Dado que la enzima SAM- sintetasa y la tRNA ${ }^{\text {Met }}$-sintetasa son parecidas estructural y funcionalmente, hace deducir que durante la evolución hubo un gen único que por duplicación ancestral generó dos enzimas, una involucrada en la ruta de la síntesis proteica y otra relacionada con la síntesis de donadores de metilos.

- Otra vía bioquímica adicional es la que compromete la biosíntesis proteica, ya que el primer aminoácido incluido en la traducción génica eucariota es la MET, y luego éste es retirado por las metioninaaminopeptidasas. Esta MET libre entra a las rutas alternas ya mencionadas.

La metionina-sintetasa es una enzima de baja Km y la cistationina- $\beta$-sintasa es una enzima alta $\mathrm{Km}$ (constante de Michaelis-Menten), esto quiere decir que a bajas concentraciones de HomCis se favorece la síntesis de MET y con altas se activa la ruta de la transulfuración evitándose el potencial tóxico de la homocisteína. ${ }^{1,41-46}$ En la Tabla 1 se consigna la genética y la genómica de las principales enzimas del metabolismo de transmetilación

\begin{tabular}{|c|c|c|c|c|}
\hline Enzima & Nomenclaturas alternativas & $\begin{array}{l}\text { Localización } \\
\text { cromosómica del } \\
\text { gen codificante }\end{array}$ & $\begin{array}{l}\text { Código } \\
\text { MIM }\end{array}$ & Enfermedades relacionadas \\
\hline $\begin{array}{l}\text { Metilene- } \\
\text { tetrahidrolato- } \\
\text { reductasa (MTHFR) }\end{array}$ & $\begin{array}{l}5,10-@ \text { metilene-tetra-hidrofolato } \\
\text { reductasa }\end{array}$ & Ip36.3 & 607093 & $\begin{array}{l}\text { - Espectro clínico de la homocistinuria. } \\
\text { - Polimorfismos de susceptibilidad en: enferme- } \\
\text { dad cardiovascular, hipertensión arterial, } \\
\text { preeclampsia, enfermedad trombótica, oclusión } \\
\text { arterial retiniana, cáncer, depresión, esquizofre- } \\
\text { nia, migraña con aura, glaucoma. } \\
\text { - Gen con polimorfismos génicos de susceptibi- } \\
\text { lidad materna en gestación de producto con } \\
\text { labio-paladar hendido y síndrome de Down. }\end{array}$ \\
\hline Metionina-sintasa & $\begin{array}{l}\text { 5-@metil-tetrahidrofolato- } \\
\text { homocisteína S-methyltransferasa } \\
\text { (MTR) } \\
\text { Tetrahidro-pteroilglutamato- } \\
\text { metiltransferasa }\end{array}$ & Iq43 & 156570 & $\begin{array}{l}\text { - Deficiencia de metilcobalamina tipo cbIG } \\
\text { (MIM250940): homocistinuria con anemia } \\
\text { megaloblástica debida a un defecto en el meta- } \\
\text { bolismo de la cobalamina, grupo de } \\
\text { complementación cblG. } \\
\text { - Gen con polimorfismos génicos de susceptibi- } \\
\text { lidad materna para gestación de producto con } \\
\text { labio-paladar hendido y síndrome de Down. }\end{array}$ \\
\hline $\begin{array}{l}\text { Metionina-sintasa- } \\
\text { reductasa (MSR) }\end{array}$ & MTRR & 5pI5.3-p/5.2 & 602568 & $\begin{array}{l}\text { - Deficiencia de Metilcobalamina tipo cblE } \\
\text { (MIM236270): homocistinuria con anemia } \\
\text { megaloblástica debida a un defecto en el meta- } \\
\text { bolismo de la cobalamina, grupo de } \\
\text { complementación cblE. } \\
\text { - Gen con polimorfismos génicos de susceptibi- } \\
\text { lidad materna para gestación de producto y } \\
\text { síndrome de Down. }\end{array}$ \\
\hline Cistationina- $\alpha$-sintasa (CBS) & & $21 \mathrm{q} 22.3$ & 236200 & - Espectro clínico de la homocistinuria. \\
\hline
\end{tabular}


y transulfuración. En la Figura 1 se muestran en forma simplificada algunos pasos en las rutas metabólicas de los sulfoaminoácidos.

\section{SAM como coordinador metabólico de la HomCis}

La SAM es un regulador alostérico de tres enzimas clave en el metabolismo de la HomCis: 1) inhibidor de la metilen-tetrahidrofolato-reductasa, 2) inhibidor de la betaína:homocisteína-metil-transferasa y 3 ) activador de la cistationina- $\beta$-sintasa. De esta forma se contrarregulan la remetilación y la transulfuración: si las concentraciones de SAM son bajas la síntesis de 5-metilentetrahidrofolato será normal, mientras que la síntesis de cistationina será suprimida, resultando en la conservación de la HomCis para la síntesis de metionina; cuando las concentraciones de SAM son altas, la HomCis al contrario del caso anterior va a ser dirigida a la ruta de la transulfuración. ${ }^{47-50}$

\section{Etiología de la hiperhomocistinemia}

Es un defecto catalogado dentro del banco MIM con el código MIM603714 y ha sido asociada con la deficien- cia de folato y cobalamina, así como con complicaciones de la gestación, defectos del tubo neural, desórdenes mentales, daño cognitivo en el geronte, psoriasis y algunas neoplasias. En Estados Unidos se ha estimado que su principal causa es la deficiencia de ácido fólico. La fortificación de los productos alimentarios básicos con esta vitamina ha disminuido la HomCis total plasmática en la población general en cerca del $8 \%$.

En desórdenes congénitos se relaciona con polimorfismos génicos en los codificantes de varias enzimas, entre las cuales están las enzimas metilene-tetrahidrolatoreductasa (MTHFR), la metionina-sintasa, la metioninasintasa-reductasa y la cistationina- $\beta$-sintasa(CBS).

Quizás el defecto genético más común asociado con moderada HipHomCis es la sustitución C677T en el gen codificante de la MTHFR, lo que lleva a una sustitución de valina por alanina en la posición 222, lo que repercute en la producción de una variante termolábil de la enzima con disminución total de su actividad que refleja una habilidad aumentada para disociarse en sus monómeros frente a la pérdida del cofactor FAD. Esta mutación es de patrón genético mendeliano autosómico recesivo y tiene variaciones entre grupos raciales y étnicos, con un 10 a 13\% (en otras series 10 a 16\%) de homozigotos $\mathrm{T} /$ T y $50 \%$ de heterozigotos $\mathrm{C} / \mathrm{T}$ entre caucásicos y asiáticos, y una muy baja incidencia en afroamericanos. El

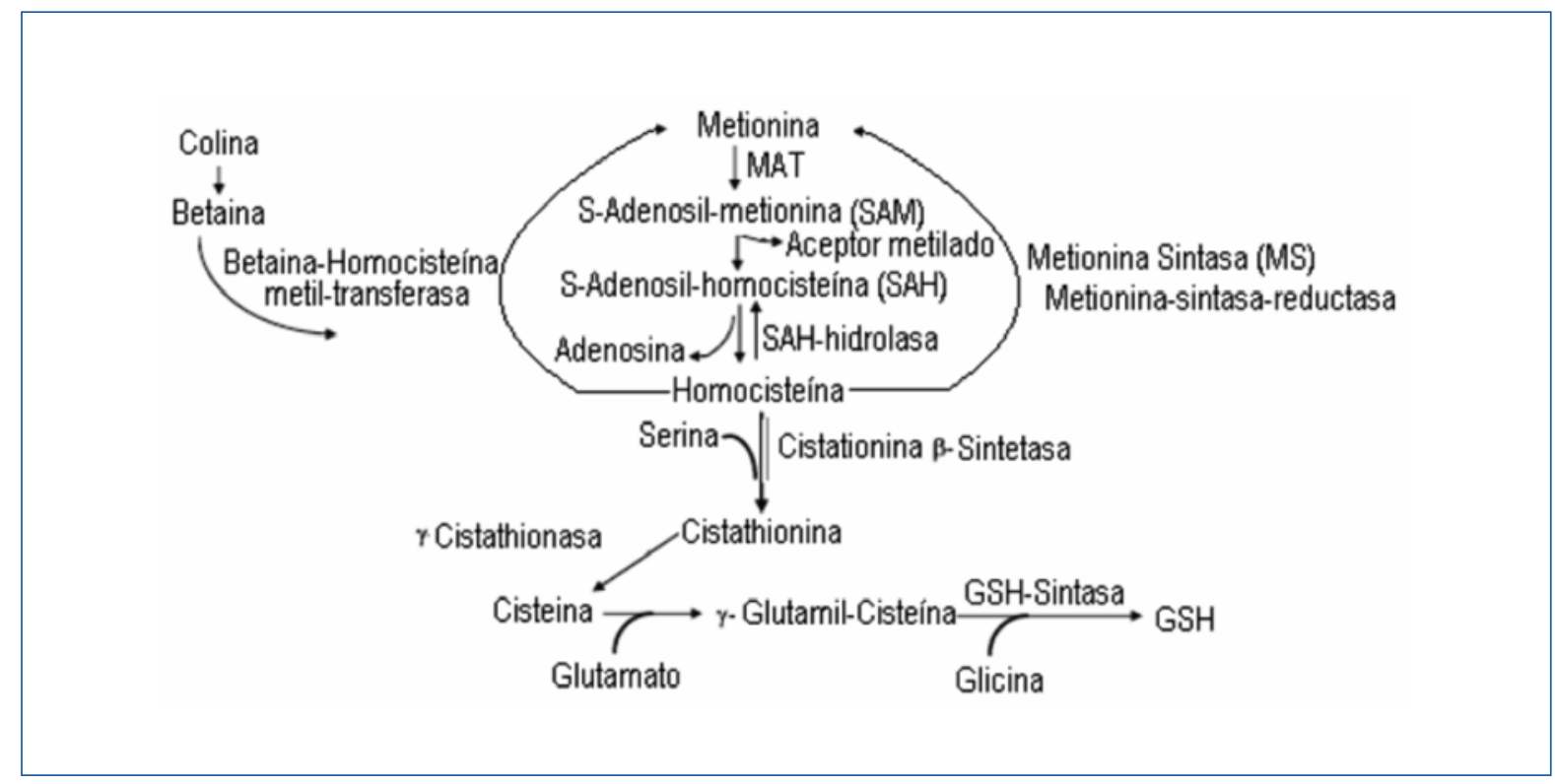

Figura I. Ciclo metabólico de sulfoaminoácidos. 
genotipo T/T lleva en algunas poblaciones al incremento de la incidencia de enfermedad cardiovascular. ${ }^{51}$

La HipHomCis puede ser el resultado de múltiples factores como sucede con medicamentos que interfieren con la actividad del ácido fólico y la vitamina B12, en especial los antimetabolitos y ciertos anticonvulsivantes. Cursan con HipHomCis:

- Enfermedad vascular (cardíaca y cerebral), ${ }^{2,3}$ afección aterosclerótica ${ }^{52}$ y complicaciones secundarias a trombofilia. ${ }^{53,54}$ La variedad moderada ha sido sugerida como un nuevo factor de riesgo independiente para enfermedad cardiovascular.

- Varias afecciones neurológicas, psiquiátricas y neuropsiquiátricas como la neurodegeneración y demencia, ${ }^{4}$ autismo, ${ }^{4,5}$, esquizofrenia, ${ }^{4,6}$ depresión ${ }^{4,6,7}$ en particular en personas gerontes ${ }^{4,6,7,8}$ y defectos del tubo neural. ${ }^{55}$

- En el síndrome de Down la relación es doble, por cuanto es un hallazgo en madres con mayor riesgo de gestar niños con esta enfermedad y los nacidos cursan con HipHomCis. Aquellos con mayores concentraciones pueden desarrollar más complicaciones neurocognitivas y cardiovasculares..$^{56,57}$

- Complicaciones gestacionales (pérdida recurrente de la gestación, preeclampsia, abrupcio placentario, trombosis venosas, entre otras). ${ }^{9,10}$

- Deficiencias vitamínicas de folato y cobalamina. También cuando se usan antimetabolitos como metotrexate (cáncer, autoinmunidad), explicando incluso así la toxicidad de estos medicamentos. ${ }^{58,59,60}$

- Enfermedades autoinmunes como psoriasis, artritis reumatoidea y lupus eritematoso sistémico. ${ }^{61,62}$

- Leucemias en las cuales se eleva el potencial de enfermedad cardiovascular y complicaciones trombóticas. ${ }^{63,64}$
- Afecciones hepáticas incluyendo la enfermedad alcohólica. ${ }^{65}$

- Diabetes. $^{66}$

- Enfermedades renales. ${ }^{67,68}$

El hecho de que se presente en éstas últimas hace pensar que gran parte de las rutas de aclaramiento de este aminoácido es el riñón y permite concatenar el hallazgo de la alta incidencia de complicaciones vasculares en pacientes renales crónicos. Diversas observaciones a partir de la metabolización in vivo de la HomCis en riñón de rata y estudios cinéticos en humanos, hacen deducir que la transulfuración renal es clave en el catabolismo de la HomCis.

\section{Hipometilación y su dinámica biológica y patobiológica}

El radio de SAM/SAHC es un buen indicador de metilación celular. La metilación es fundamental para la biosíntesis de fosfolípidos, ácidos nucleicos, aminas y otros neurotransmisores; la regulación de la expresión génica mediada por metilación de histonas y promotores génicos, y la metilación postraduccional de proteínas, son reacciones mediadas por las metil-transferasas. La SAHC es un inhibidor potente de múltiples metil-transferasas, lo cual permite entender que la HipHomCis causa toxicidad por hipometilación (Figura 2). En circunstancias fisiológicas y homeostásicas, la enzima SAHC-hidrolasa está catalizando este inhibidor de transferasas. Hay reportes de la asociación temporoespacial coordinada entre las metil-transferasas y la SAHC-hidrolasa, y como hallazgo adicional en bioquímica estructural, los sitios catalíticos de ambas enzimas pueden unir SAHC, en el primer caso para inhibir y el segundo caso para ser degradada.

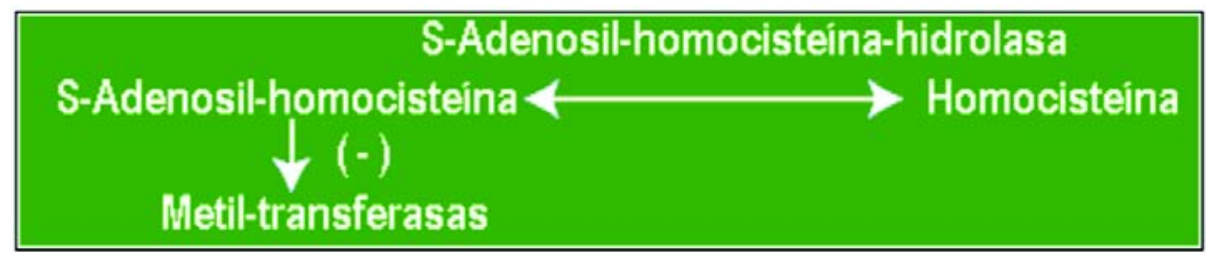

Figura 2. Inhibición de las metil-transferasas por SAHC. 
Una de las proteínas que de manera normal presenta carboxi-metilación en el control del ciclo celular es p21Ras, y esto inhibe la proliferación en células vasculares endoteliales, pero no en células vasculares musculares. Las reacciones de transmetilación son esenciales como mecanismo de respuesta al estrés por parte de los eritrocitos, dado que ellos sufren modificaciones postraduccionales espontáneas que vulneran la estructura del plasmalema. Esto se ha demostrado gracias a que en circunstancias particulares como el envejecimiento aumenta la concentración de proteínas metiladas de membrana en el eritrocito, pero en insuficiencia renal crónica y en pacientes en hemodiálisis los niveles de HomCis son elevados, por tanto las cifras de SAHC son altas y esto condiciona hipometilación en el eritrocito y la anemia de la insuficiencia renal crónica. Hallazgos similares se ven en enfermedad arterial oclusiva periférica.

Por último, es importante anotar que los patrones de represión y activación de la expresión genética dependen de modificaciones postraduccionales como la metilación. Esto nos permite determinar que la metilación de la cromatina (material genético e histonas) tiene que ver en cómo se orquestan los genes para que se expresen o se repriman dentro de los algoritmos de los programas genéticos, lo que hoy se llama epigenética. Estos patrones de metilación en la cromatina son altamente regulados y modulados por la interacción con el ambiente, y en este caso con el ambiente tisular y sistémico, con una deficiencia de intermediarios metilos. La hipometilación resultante puede llevar a que genes que no se estén expresando se expresen y ello decaiga en alteraciones funcionales como en cáncer. ${ }^{69-72}$

\section{Homocisteína plasmática}

Es evidente que el exporte de HomCis al medio extracelular es un signo de imbalance entre la producida y su metabolismo. Partiendo de esto tenemos dos situaciones distintas: 1) cuando la HomCis está baja su exportación es mayor porque la actividad de la metionina-sintasa es muy baja. Una circunstancia igual sucede con la pobre disponibilidad de ácido fólico y/o vitamina B12.2) Si la HomCis está alta la exportación incrementa con disminución de la actividad de la cistationina- $\beta$-sintasa, es decir de la ruta de la transulfuración.
La salida de la HomCis desde la célula no está clara y se hace a través del transportador de eflujo llamado sistema L. Por otro lado hay un rasgo bioquímico estructural interesante consistente en que el grupo amino de la homocisteína-thiolactona tiene una constante $\mathrm{pKa}$ baja ( 7.1) inusual, comportándose a pH fisiológico como una molécula neutra que permea de manera libre la membrana plasmática.

En el plasma sanguíneo se encuentran varias formas estructurales de la HomCis, tanto oxidada (99\%) como reducida (1\%), o bien libre (25\%) unida a proteínas Hcyproteína-disúlfidos (75\%). En terminología internacional esta última se conoce como bHcy y la libre como fHcy. Se ha encontrado que hay rápido equilibrio de redistribución entre la HomCis libre y la unida a proteínas. El grupo thiol de la HomCis puede formar puentes disulfuro con otra HomCis formando homocistina HcyS-S-Hcy, con cisteína libre Hcy-S-S-Cys o con grupos thiol de proteínas plasmáticas como la albúmina. En general el total de las formas estructurales de la HomCis en plasma son cobijadas como HomCis total.

Los factores con influencia sobre las concentraciones plasmáticas de HomCis son demográficos, genéticos, fisiológicos y adquiridos (hábitos, nutrición, enfermedad, trasplantes y medicación). Las cifras normales en plasma están en el rango de 5 a $16 \mu \mathrm{mol} / \mathrm{L}$, aunque algunos autores estiman que $10 \mu \mathrm{mol} / \mathrm{L}$ sea el límite superior deseable, si se hace la corrección adecuada en la dieta con vitamina B6, B9 y B12. Los valores elevados se denominan moderado $(16-30 \mu \mathrm{mol} / \mathrm{L})$, medio $(30-100 \mu \mathrm{mol} / \mathrm{L})$ y severo $>100 \mu \mathrm{mol} / \mathrm{L})){ }^{73,74}$ En la Figura 3 se muestra la estructura química y la terminología especializada de la HomCis y sus derivados.

\section{Homocisteína-}

\section{thiolactona(HCTL) y la homocisteinilación como modificación postraduccional proteica}

La HomCis puede activarse junto con el tRNA ${ }^{\text {Met }}$ para metionina (tRNA ${ }^{\mathrm{Met}}$ ) hacia homocisteininatRNA ${ }^{\mathrm{Met}}$ por medio de la enzima metionil-tRNA ${ }^{\text {Met }}$-sintetasa. Esto 


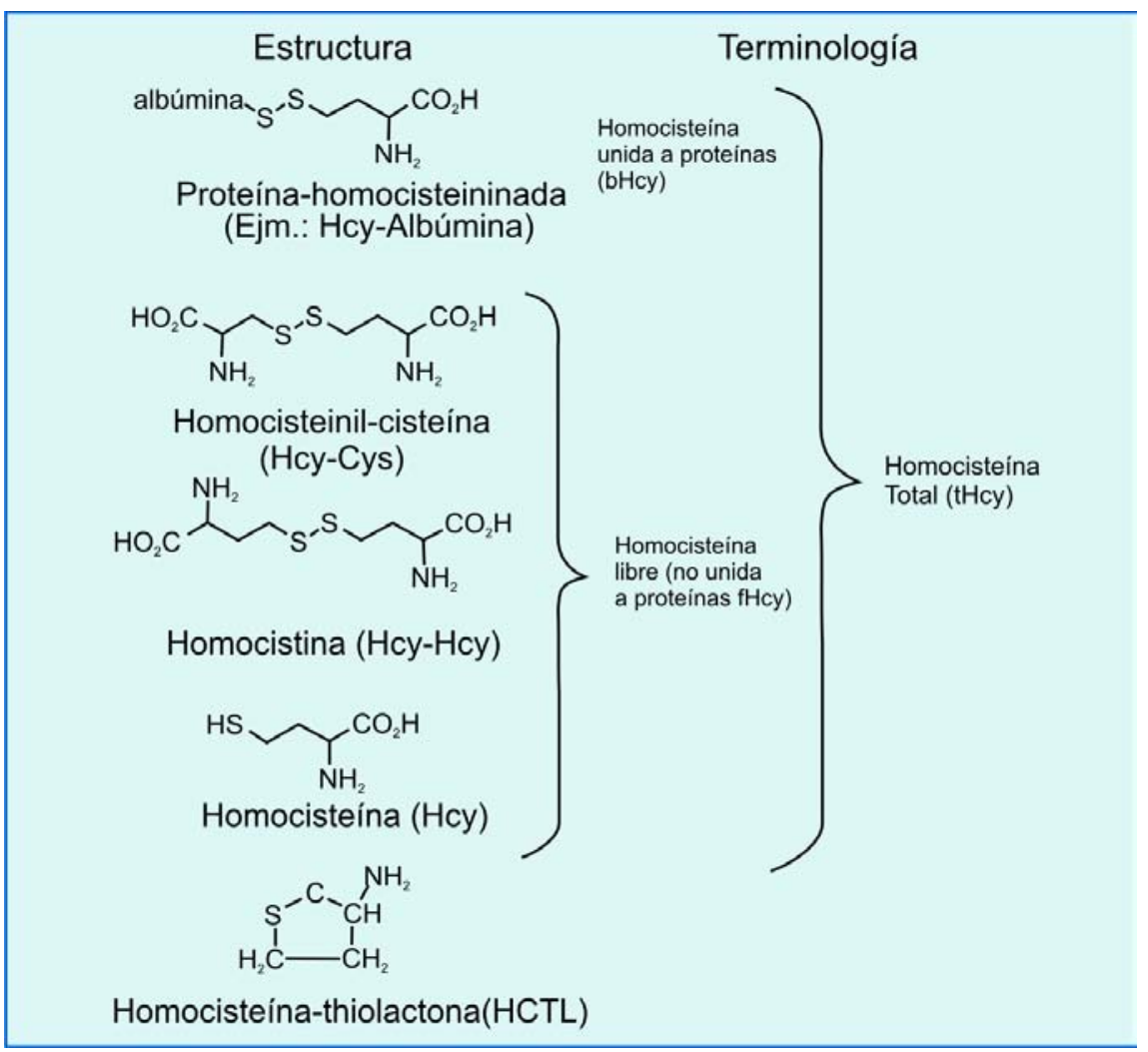

Figura 3. Estructuras químicas de la homocisteina y su terminología.

quiere decir que la HomCis es activada como si fuera un aminoácido que va a entrar a la traducción génica o biosíntesis proteica. Lo anterior resultaría ser ilógico, pero sólo hasta que se encontró que hay rápida metilación de la HomCis hacia metionil-tRNA ${ }^{\text {Met }}$, se entendió por qué no hay en la normalidad HomCis dentro de las proteínas. Un mecanismo salvatorio es la afinidad per se de la

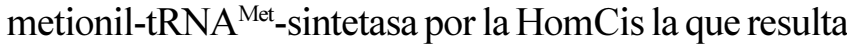
ser cien veces menor que por la MET.

La HomCis también puede ser tomada por otras enzimas activadoras como la isoleucil-tRNA ${ }^{\mathrm{Ile}}$-sintetasa, la leuciltRNA ${ }^{\text {Leu}}$-sintetasa e incluso la valil-tRNA ${ }^{\text {Val }}$-sintetasa y la lisil-tRNA ${ }^{\text {Lis }}$-sintetasa, lo que se explica por la homología estructural de la HomCis, con la MET, la isoleucina y la leucina. Cuando esta metilación no es eficiente, el homocisteinil-tRNA ${ }^{(\text {Ile, Leu, Val, o Leu }) ~ e s ~ c o n v e r t i-~}$ do hacia homocisteína-thiolactona (HCTL), por cualquiera de esta tRNA-sintetasas. Esta promiscuidad es más grande de lo que se piensa y limitada en otros casos, es así que la isoleucil-tRNA ${ }^{\mathrm{Ile}}$-sintetasa puede activar la valina, mientras que la tirosil-, la cisteinil- y la arginiltRNA-sintetasas son bastante específicas.
En las bacterias gram negativas hay un fenómeno llamativo, en el cual lisil-, valil- e isoleucil-tRNA pueden activar la homoserina hacia homoserina-lactona (HSL), la cual es una feromona bacteriana que sirve para determinar densidad de población, pero es curioso que también muestra actividad vasorrelajante en músculo liso vascular e induce la apoptosis de leucocitos (macrófagos y neutrófilos). Se desconoce si la HSL pueden producir modificaciones en las proteínas de manera similar al HCTL. La cisteinil-tRNA ${ }^{\text {Cys }}$-sintetasa puede editar cisteína hacia cisteína-thiolactona.

Este proceso de activación y edición de la HomCis tiene su costo porque necesita ATP. Se estima que este alto costo energético en presencia de HipHomCis tiene efecto proapoptótico que al parecer es del tipo prooxidativo o desencadenado por estrés de radicales libres, ya que puede ser neutralizado por antioxidantes.

La HomCis puede ser introducida en forma anómala dentro de la biosíntesis proteica sólo si se modifica por nitrosación hacia s-nitroso-homocisteína, que es uno de los s-nitrosothioles más estables en el plasma, con una 
vida media de cerca de 1.5 horas. Esta nitrosación está dada por NO a concentraciones altas (micromolares) y por sus derivados RNS (especies radicales derivadas del nitrógeno). La s-nitrosohomocisteína no es editada hacia HCTL. Hoy se considera que el $50 \%$ de la HomCis en proteínas es dada por este mecanismo y el restante $50 \%$ lo da la reactividad de la HCTL.

Dado que la HCTL tiene un enlace thioéster de alta energía (Figura 3), es muy reactiva y con facilidad puede alquilar (o acilar) aminoácidos como la asparragina, arginina, glutamina y en especial lisina y cisteína, llevando a lo que se denomina como proteínahomocisteinilación, homocisteinilación o formación de aductos proteicos homocistamida. Se habla de n-homocisteinilación cuando toma cualquier aminoácido distinto a la cisteína, y s-homocisteinilación cuando toma cualquier aminoácido distinto a la cisteína y s-homocisteinilación cuando toma a la cisteína. Este tipo de modificación con sulfoaminoácidos no es tan atípica como se esperaría, sucede también con el glutatión y sus derivados, generando s-cysteinilglicinilación, s-glutathionilación, y s-cisteinilación de proteínas. En la Figura 4 se muestra el proceso de homocisteinilación.

Este tipo de modificación postraduccional, es decir después de que fue sintetizada la proteína, afecta la función de la proteína, como sucede con la tripsina que la inactiva. En el caso de la s-homocisteinilación la adición de un puente disulfuro intra o intermolecular cambia la estructura terciaria de la proteína y por ende su función. También altera también la afinidad por sus ligandos o por otras proteínas. Otro cambio significativo es que un grupo thiol adicional altera la carga eléctrica local y neta de la molécula, haciendo que la proteína sea más susceptible al daño oxidativo.

La escala y grado de la homocisteinilación depende de varios factores pero al principio de la producción de HCTL. Elevadas concentraciones de HomCis promueven la alta concentración de HCTL. Las células procariotas producen más HCTL que las eucariotas, dado que las bacterias contienen más homocisteína. Una alta concentración de MET decrementa la síntesis de HCTL y el poco HCTL sintetizado a partir de la MET se metaboliza por la vía SAM-SAHC. Ante todo hay que aclarar que la interrelación entre los niveles de HomCis y el grado de homocisteinilación in vitro está bien establecido y documentado, pero in vivo es menos entendido. Así, se ha encontrado que aunque los niveles de homocisteína se encuentren elevados en pacientes hemodializados, no hay estricta proporcionalidad con la homocisteinilación en plasma, incluso resultando no ser claro esto si se parte de otro estipendio como es la actividad reducida de la PON1 en falla renal.

Los niveles $\mathrm{p}$ de HCTL en plasma humano varían entre 0 y $35 \mathrm{nM}(2.82+/-6.13 \mathrm{nM})$, que es cerca del 0.002-

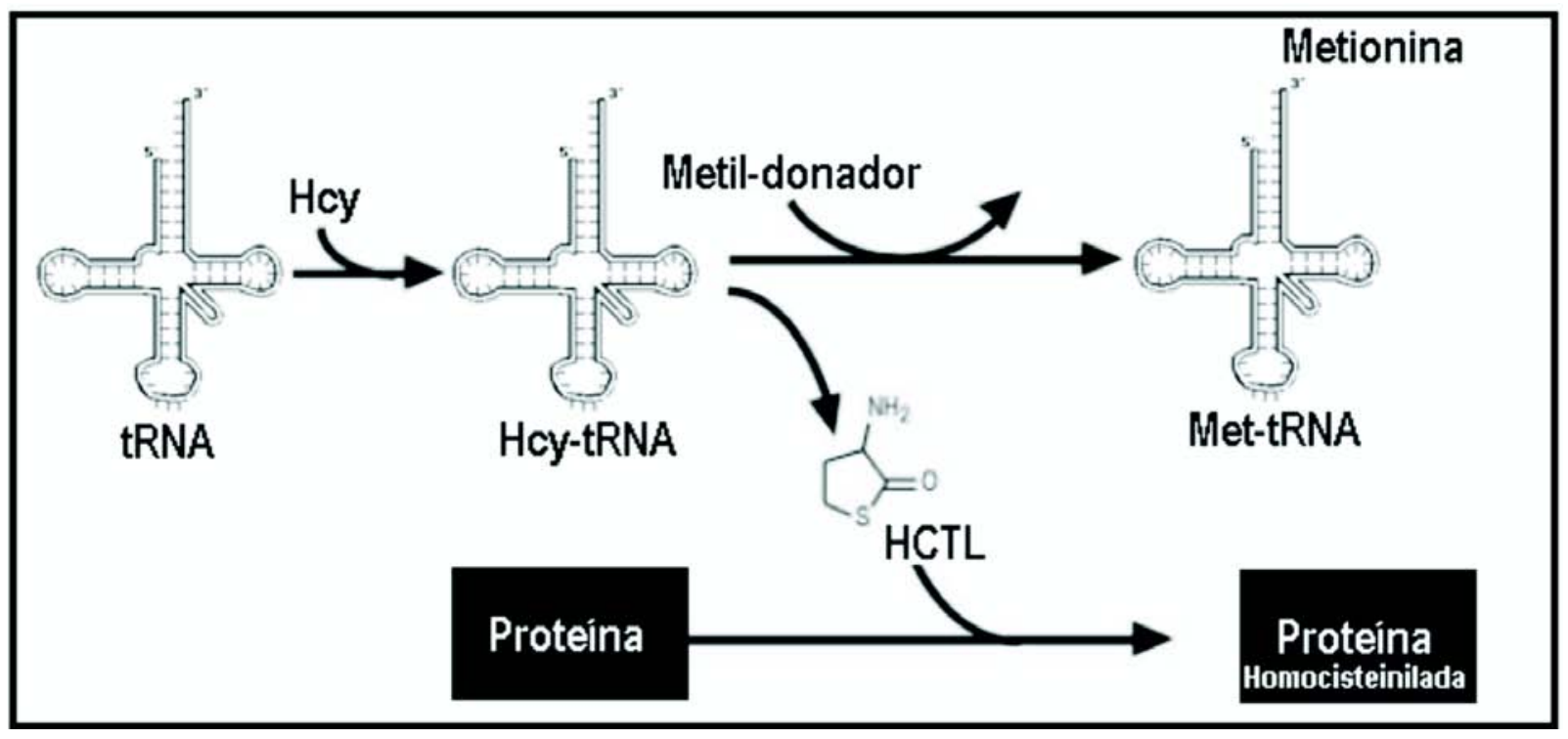

Figura 4. Proceso de homocisteinilación. 
$0.29 \%$ del total de la HomCis total plasmática. Tiende a ser más elevado en hombres, en los de mayor edad, pero aún no se ha corroborado si estas variaciones tienen significancia estadística. Mientras que las cifras de HomCis urinaria y sanguínea son similares, los de HCTL urinario son superiores a $145 \mathrm{nM}(11-474 \mathrm{nM})$ lo cual corresponde entre 2.5 y $28 \%$ de la HomCis total urinaria. Recordemos que las fracciones de HCTL urinaria y sanguínea forman parte del total de la HomCis urinaria y plasmática.

Otro dato que se ha elucidado a partir de esto es que mientras el aclaramiento de HomCis es el 0.1 a $0,3 \%$ del acalaramiento de creatinina, la HCTL puede llegar a ser el 20 a $700 \%$ de esta medida, lo que pone de manifiesto que no sólo hay filtración glomerular sino también secreción tubular, pero no ha sido excluida la producción endógena en este órgano. La excreción urinaria de HCTL es de 300 a $400 \mathrm{nM} /$ día y puede variar dependiendo del $\mathrm{pH}$, ya que la alcalinización urinaria puede producir hidrólisis espontánea de la molécula.

La HCTL se une a varias proteínas a $\mathrm{pH}$ y temperatura fisiológicos, tales como albúmina, fibrinógeno, transferrina, á2-macroglobulina, mioglobina y citocromo C. Se ha estimado que en el plasma el $0,36 \%$ de la albúmina y el $0,6 \%$ de la hemoglobina están homocisteiniladas, lo que hace equiparar que por cada millar de MET en una proteína existe una de HomCis ligada a un residuo de lisina. En el caso de las gammaglobulinas, la LDL, la HDL, antitripsina, transferrina y fibrinógeno, el estimado de homocisteinilación es del 0,04 a 0,1\%. La albúmina se considera que es el principal reservorio plasmático de HomCis, por cuanto lleva el $90 \%$ del total, pero si se toma la sangre total se tiene que sólo es el almacén del $22 \%$, la hemoglobina prima con el $75 \%$ y un $2 \%$ para las gammaglobulinas. Visto de otra forma, lo que habíamos llamado como HomCis total (en plasma) corresponde al $25 \%$ del total de la homocistamida de sangre y el $75 \%$ es eritrocitaria unida a hemoglobina. Hay proteínas del plasma que no son homocisteiniladas, teniendo como ejemplo la prealbúmina o también denominada transtiretina, a pesar de que tiene siete residuos de lisina.

Volviendo al caso de la albúmina tenemos que la shomocisteinilación sucede preferencialmente en la cisteína en la posición 34 y la n-homocisteinilación en la lisina en la posición 525. La albúmina se considera que puede funcionar como un amortiguador plasmático frente a la patógena homocisteinilación tisular. La shomocisteinilación de la albúmina hace que sea más susceptible a la proteolisis y por otra parte la albúmina nhomocisteinilada se cataboliza más rápido por el hígado, lo que sugiere que esta es la forma en que este órgano detoxifica la HCTL.

El mayor número de HCTL que active una proteína depende de la menor o mayor cantidad de lisinas que tenga. El hecho de que proteínas de alto peso molecular con muchas lisinas sean poco homocisteiniladas se explica porque estas lisinas están crípticas dentro de las estructuras proteicas secundaria y terciaria. Por otro lado, la homocisteinilación puede inactivar proteínas, así tenemos

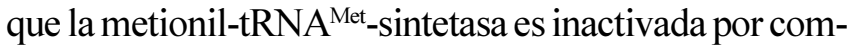
pleto cuando un tercio de sus lisinas están nhomocisteiniladas y la tripsina necesita para ello que el $90 \%$ de sus residuos lisil lo estén.

Aquellas proteínas con dominios del tipo EGF (epidermal growth factor) presentes en proteínas de la matriz extracelular como las fibrillinas, factores de la coagulación o los receptores para lipoproteínas (LDL-R), son blanco de alta afinidad para sufrir homocisteinilación. Esto permitiría explicar el rol de la HipHomCis en la enfermedad cardiovascular y lo que es más, en el contexto del síndrome metabólico..$^{75-78}$

Las lipoproteínas de alta densidad (HDL) poseen una homocisteína-thiolactona-hidrolasa dependiente de calcio, cuya mayor producción es hepática, susceptible a inhibición por penicilamina e isoleucina, que representa un mecanismo protector a la patógena homocisteinilación. Esta thiolactonasa también degrada el fenil-acetato, p-nitrofenil-acetato y ciertos organofosforados (paraoxon, diazoxon, soman, sarin). Esto último permitió determinar que la enzima como tal es en realidad un grupo de enzimas clasificadas dentro del IUMBM como EC 3.1.1.2, que se conocen hoy como las paroxonasas (PON), de las cuales en la especie humana se reconocen tres: PON1, PON2 y PON3. La PON1 es quizá la más importante de este grupo y así mismo la más estudiada, siendo detectada en tejidos pero a concentraciones más bajas que las plasmáticas. La PON2 no circula en plasma pero es de expresión 
pantisular y la PON3 es plasmática pero está en dos órdenes de magnitud menor al respecto de su concentración al compararla con PON1.

Se han detectado varios polimorfismos en el gen PON1, siendo bien estudiados a la fecha:

- R192Q (o arginina192glutamina) que origina tres pares alélicos: RR, RQ y QQ.

- M55L (metionina55leucina) que origina tres pares alélicos: MM, ML y LL.

- la variación en el promotor C (-108)T.

La enfermedad cardiovascular parece ser más frecuente en los homozigotos RR que en los homozigotos QQ o heterozigotos. El genotipo MM se asocia con bajas concentraciones de PON1 en plasma. Así, los individuos que son genotipo homozigoto QQ/LL tienen alta protección cardiovascular contra la HipHomCis. La PON1 hidroliza varias lactonas aromáticas y alifáticas, y es cuatro veces más eficiente catabolizando los isómeros L- que variedades D- como la D-homocisteína-thiolactona ${ }^{79-83}$ Las PON también se habían determinado como enzimas metabolizantes de fosfolípidos, pero actualmente se ha dilucidado la existencia de un tipo particular de fosfolipasa A2(PLA2) que puede hacer ello. La PON1 es la responsable por el efecto antiaterosclerótico de las HDL y los bajos niveles plasmáticos de estas enzimas son un predictor independiente en enfermedad cardiovascular. En la Tabla 2 se lista la genética y la genómica de las PON.

\section{La fosfolipasa A2 de las lipoproteínas y no las PON}

Es claro hoy que el catabolismo de lípidos anómalos en las lipoproteínas de la placa aterosclerótica no la hacen las PON sino una PLA2 que corresponde al subtipo PLA2G7, secretoria inflamatoria mieloide, conocida como acetil-hidrolasa para los factores activadores plaquetarios (PAF-AH), enzima producida por células inflamatorias de origen mieloide que se caracteriza por estar en estrecha asociación con lipoproteínas plasmáticas y lesiones ateroscleróticas muy vulnerables. La PLA2G7 degrada tanto los PAFs como los ácidos grasos de cadena corta oxidados a partir de la posición sn2 de los fosfolípidos. Se han encontrado dos genes codificantes de enzimas con esta actividad PAFAH1A, uno localizado cromosómicamente en 6p21.2-p12, ha sido bien estudiado y corresponde a la gran actividad en el plasma. El otro gen denominado PAFAH2 se localiza en 1p34.3 y codifica una enzima intracelular.

El verdadero rol de la PLA2G7 en el síndrome metabólico y en especial en el componente aterosclerótico no es claro, dado que por un lado la degradación de los PAF sería antiinflamatoria y antiaterógena puesto que los PAF son MCC con reconocida actividad proinflamatoria y proactivadora inmune de amplio espectro. Por otro lado, el producto del catabolismo de los PAF son los LPC, que junto con la degradación de fosfolípidos oxidados, con la consecuente liberación de ácidos grasos no esterificados modificados por oxidación no son potentes proinflamatorios y proaterógenos.

\begin{tabular}{|c|c|c|c|c|}
\hline Enzima & $\begin{array}{l}\text { Nomenclaturas } \\
\text { alternativas }\end{array}$ & $\begin{array}{l}\text { Localización } \\
\text { cromosómica del } \\
\text { gen codificante }\end{array}$ & Código MIM & $\begin{array}{l}\text { Enfermedades } \\
\text { relacionadas }\end{array}$ \\
\hline PONI & $\begin{array}{c}\text { Paroxonasa plasmática } \\
\text {-Arilesterasa } \\
\text { Esterasa } A(E S A)\end{array}$ & $7 q 21.3$ & 168820 & $\begin{array}{l}\text { - Gen de susceptibilidad a enferme- } \\
\text { dad coronaria } \\
\text { - Gen de sensibilidad en intoxica- } \\
\text { ción por organofosforados }\end{array}$ \\
\hline PON2 & & $7 q 21.3$ & 602447 & $\begin{array}{l}\text { - Polimorfismo génicos asociados } \\
\text { con enfermedad coronaria y a dia- } \\
\text { betes mellitus tipo } 2\end{array}$ \\
\hline PON3 & & $7 q 21.3$ & 602720 & - Aún no \\
\hline
\end{tabular}


En últimas, se ha estimado que el efecto final depende del rango y predominio de distribución de la PLA2G7 entre las OxLDL (lipoproteínas de baja densidad oxidadas) y las HDL (lipoproteínas de alta densidad). Lo que sí es definitivo hoy es que la elevación de la PLA2G7 es un marcador de inflamación y la experimentación ha demostrado que su inhibición dirigida y específica puede tener contundentes efectos antiaterógenos. Varios estudios como el WOSCOPS (West of Scotland Coronary Prevention Study), el MONICA (Monitoring Trends and Determinants in Cardiovascular Diseases) y los RC (Rotterdam cohorts), han demostrado que la PLA2G7 es un predictor independiente a largo plazo de enfermedad cardiaca coronaria y enfermedad cerebrovascular. El nexo entre inflamación y dislipidemia desde la panorámica de la PLA2G7 es aún bastante complejo, puesto que si bien la activación de PLA2G7 posee una finalidad proinflamatoria predominante en el síndrome metabólico parece estar regulada de manera positiva en estados dislipidémicos como una medida salvadora para facilitar el aclaramiento de lípidos. ${ }^{84-87}$

\section{La metilación a demanda: un determinante clave del metabolismo de la homocisteína}

Un evento claro es que hay tanta HomCis como MET utilizada en reacciones de metilación. El concepto de metilación a demanda se refiere a situaciones que ocurren con adecuada ingesta de MET. Cuando es excesiva no se habla de metilación a demanda, y este exceso se desvía por las rutas de transulfuración y transmetilación. Al saturarse se activa la ruta de glicina- nmetiltransferasa (GNMT).

Cuando hay metilación a demanda, es obligatorio hablar de los procesos donde participan las metiltransferasas. Si bien existen varias de ellas hay dos que desde el punto de vista cuantitativo son fundamentales: la guanidinoacetato-metiltransferasa, clave en la producción de creatina (Figura 5) y la fosfatidiletanolaminan-metiltransferasa (PEMT), enzima hepática básica para la producción del fosfolípido denominado fosfatidilcolina (Figura 6). La reacción catalizada por la PEMT utiliza tres moléculas sucesivas de SAM y cataliza la biosíntesis del $30 \%$ del total de la fosfatidilcolina en el hígado, el $70 \%$ restante se hace por la vía de Kennedy, la cual utiliza la colina como sustrato con dos pasos enzimáticos posteriores.

La biosíntesis de creatina es considerada la mayor usuaria de los grupos metilos provenientes de SAM, determinándose que hasta el $75 \%$ de la HomCis formada proviene de esta ruta. En razón a lo anterior se ha encontrado que la ingesta de creatina o guanidinoacetato en murinos, disminuye los niveles de HomCis. Hay mecanismos particulares donde se necesita metilación: la de la L-DOPA en pacientes con enfermedad de Parkinson y en la transmetilación hepática del alcohol. En enfermos con Parkinson que reciben tratamiento con L-DOPA, los niveles de HomCis están hasta 50\% más elevados que en sujetos control. Esto se explica porque la L-DOPA es substrato para la catecol- $O$-metiltransferasa, la cual

\section{ARGININA + GLICINA $\longrightarrow$ Ornitina + Ácido guanidino-acético \\ \begin{tabular}{l|l} 
AGAT & GAMT
\end{tabular} \\ (Riñón) (Higado) \\ Enzimas: \\ AGAT=L-arginina:glicina-amidino-transferasa \\ Creatina \\ GAMT=S- adenosil-L-metionina:guanidinoacetato-metiltransferasa}

Figura 5. Biosíntesis de la creatina. 


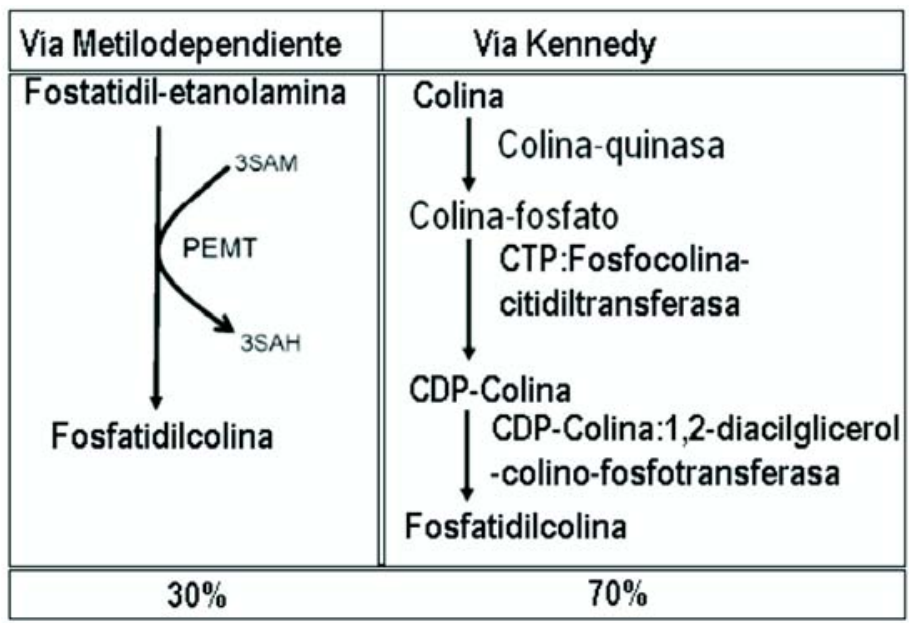

Figura 6. Biosíntesis de la fosfatidilcolina (lecitina).

cataliza la metilación dependiente de SAM. En modelos murinos la HipHomCis se atenúa con inhibidores de la COMT. $^{88,89}$

\section{Las reacciones de transmetilación en enfermedad hepática alcohólica}

El consumo de etanol daña el metabolismo de la MET. El resultado final es que como parte de las reacciones de destoxificación se disminuyen los niveles hepatocitarios de SAM e incrementan los de homocisteína y SAHC. Esto reduce las reacciones esenciales de metilación a causa de la inhibición de varias metiltransferasas, tales como la fosfatidiletanolamina-metiltransferasa (PEMT) importante en la generación del fosfolípido fosfatidilcolina, la isoprenil-cisteína-carboxil-metil-transferasa (ICMT) fundamental para catalizar la metilación postraduccional de la cisteína c-terminal isoprenilada encontrada en muchas proteínas de señalamiento como las $\mathrm{G}$ monoméricas, y la proteína-L-iso-aspartato-metiltransferasa (PIMT), enzima esencial de reparación en sitios iso-aspartil de proteínas espontáneamente dañadas.

Se ha encontrado que la disminución de la actividad de estas enzimas se asocia con mayor depósito de grasa, incremento de la apoptosis y acumulación de proteínas anómalas, lo que se denomina estrés proteico en el retículo endoplásmico rugoso. Esto ha postulado que el uso de agentes remetilantes de la HomCis como la betaína, sean una esperanza en el manejo inteligente biológico de la enfermedad hepatoalcohólica.

También se sugiere que la terapia con betaína aumenta de manera indirecta los niveles de glutatión, un cofactor del metabolismo hepático con potencial reductor y antioxidante, dado que la HomCis puede ser condensada con la serina produciéndose cistathionina y esta ser clivada por la ã-cistathionasa hacia cisteína, importante precursora del tripéptido glutatión. Incluso se ha pensado en la suplementación directamente con colina, creatina, SAM y ácido fólico. La experimentación en murinos e inicial en humanos es promisoria.

Por otro lado la disminución de SAM es un elemento clave en la génesis de la inflamación, la cirrosis y el hepatocarcinoma pues el SAM induce una disminución en la producción del factor de necrosis tumoral alfa (TNFá) y una elevación de la interleucina-10 (IL10). Esto induce un fenotipo antiinflamatorio anticirrótico e incluso antineoplásico. Además es un modulador del crecimiento, la muerte y la diferenciación de hepatocitos. El SAM es antiapoptótico en hepatocitos normales y es proapoptótico en hepatocitos cancerosos. Este último efecto es dependiente de la inducción génica de la proteína proapoptótica Bcl-Xs. ${ }^{65,90-95}$ En la Figura 7 se consignan en un diagrama estas interacciones. 


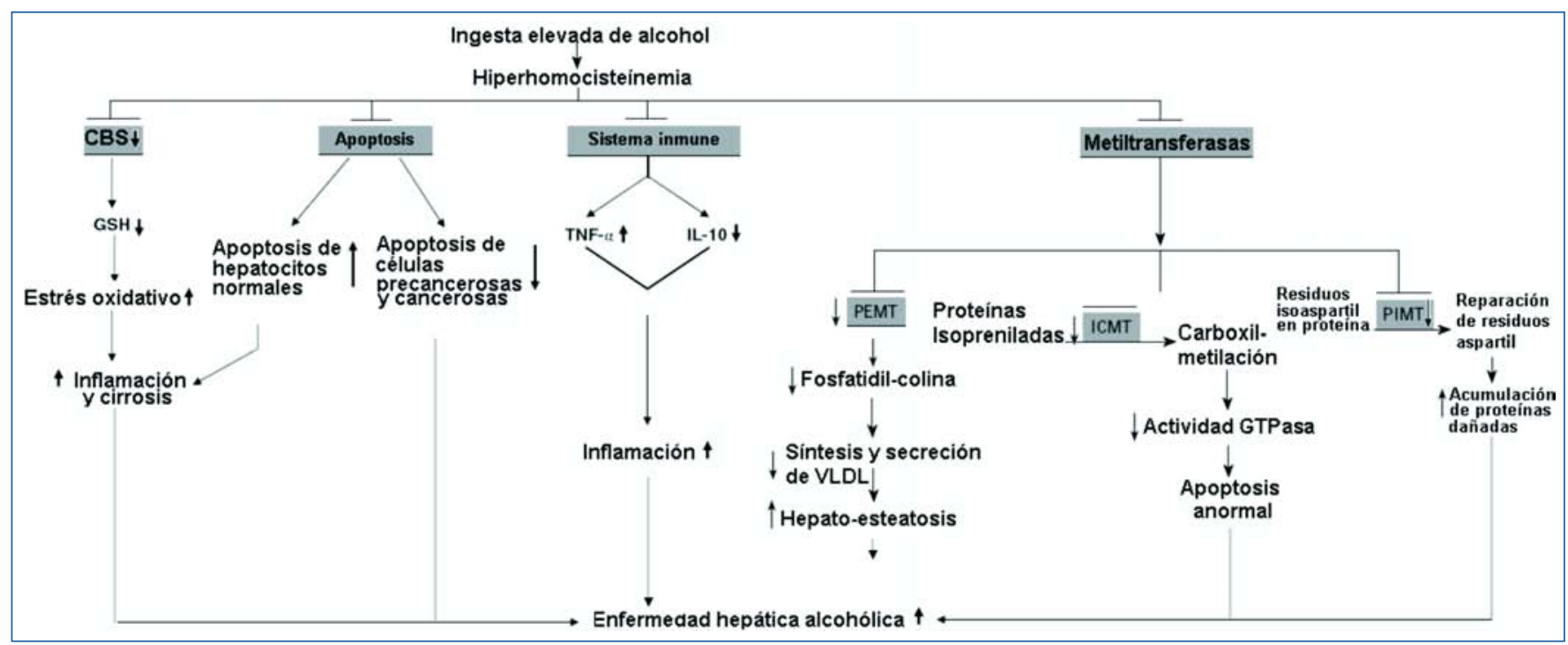

Figura 7. Hiperhomocisteinemia y enfermedad hepática alcohólica.

\section{Hiperhomocistinemia y enfermedad cardiovascular}

La HomCis in vitro e in vivo ha mostrado ser un prooxidante directo e indirecto, barredor de moléculas tróficas como el NO, procoagulante y proapoptótico. Desde la descripción en 1962 de Carson y Neill de la asociación de la homocistinuria con retardo cognitivo, ha aumentado el espectro de asociaciones y complicaciones, en particular con enfermedad cardiovascular. La homocistinuria es un cuadro que cursa con episodios de tromboembolismo, retardo mental, dislocación del cristalino, esteatosis hepática y osteoporosis. Ya en 1969 McCully encontró la toxicidad endotelial de la HomCis y en 1975 el mismo investigador formulaba su teoría de la HomCis en la aterosclerosis. En 1976 se publica el primer estudio sobre riesgo cardiovascular por HipHomCis por los investigadores Wilcken \& Wilcken (J Clin Invest 1976 Apr;57 (4): 1979-82) y formalmente en 1991 se reconoce tal potencial en diversos estudios (NEng J Med. 1991 Apr 25; 324 (17): 1149-55; N Engl J Med. 1985 Sep 19;313(12):709-15).

Desde el punto de vista genético la homocistinuria es causada por una mutación homozigota de la enzima CBS, mientras que la HipHomCis puede deberse a mutación heterozigota de CBS y la variante C677T de la MTHFR. Varios estudios sugieren que la HipHomCis moderada es un factor de riesgo para ciertas poblaciones, en espe- cial aquellas con estilos de vida no saludables. Boushey y colaboradores en 1995, demostraron que una elevación tan pequeña como de $5 \mu \mathrm{M}$ puede incrementar el riesgo de enfermedad arterial coronaria tanto como $60 \%$ en el hombre y $80 \%$ en la mujer.

La HipHomCis puede causar daño directo por mecanismos como la homocisteinilación proteica o indirecto a través de la generación de estrés oxidativo (generación de peróxido de hidrógeno ó $\mathrm{H}_{2} \mathrm{O}_{2}$ produciendo en ambas rutas efectos vasopáticos del tipo vasoconstricción, protrombosis y proaterosclerosis. Parte de estos efectos surgen de la modulación anómala de enzimas antioxidantes como la glutatión-peroxidasa-1(GPx-1) ${ }^{96}$ y la biodisponibilidad del óxido nítrico. ${ }^{97}$

La HipHomCis ha sido relacionada con varios defectos a nivel endotelial, de la coagulación y metabólico lipídico como:

- Homocisteinilación de la ApoB100 de la LDL.

- Aumento de la unión de la LDL a la fibrina.

- La LDL homocisteinilada es más susceptible a oxidación y se acelera también su fagocitosis por macrófagos espumosos, sin contar que ésta dirige la formación de autoanticuerpos. Al respecto de estos anticuerpos se han hecho estudios que correlacionan sus concentraciones con varios índices de 
aterosclerosis como el engrosamiento de la íntima y media de la arteria carótida. Son específicos contra proteínas homocisteiniladas y no contra HomCis libre, LDL nativa y OxLDL. Otro estudio encontró que estos anticuerpos están en un rango $20 \%$ mayor en hombres con accidente isquémico cerebral al compararlos con controles sanos.

- La LDL homocisteinilada disminuye la actividad de la bomba sodio/potasio-ATPasa, con sobrecarga de sodio y calcio que se asocian con baja síntesis de $\mathrm{NO}$ a rango nanomolar entedotelio-trófico, favoreciendo la vía alterna del NO hacia la biosíntesis de radicales nitroxidativos.

- Reducción de la activación del anticoagulante proteína $\mathrm{C}$.

- Inhibición de la antitrombina III (ATIII).

- Inhibición de la síntesis del anticoagulante heparánsulfato presente en proteinglicanos como la trombomodulina.

- Inhibición de la unión al endotelio del activador tisular del plasminógeno (tPA).

- Inducción independiente de trombina, del factor $\mathrm{V}$ (de Leiden) de la coagulación.

- Un mecanismo natural de neutralización de la Hom $\mathrm{Cis}$ es el NO, el cual a concentraciones normofisiológicas (rango nanomolar) puede formar s-nitroso-homocisteína que actúa sobre plaquetas e induce un potencial antitrombótico.

- Inhibición de la unión de la superóxido-dismutasa 3 (SOD3) al endotelio, impidiendo el potencial antioxidante de esta enzima.

- Incremento de la senescencia replicativa endotelial.

- La n-homocisteinilación de los residuos de lisina en el colágeno, como el tipo IV subendotelial, puede causar alteraciones estructurales del mismo, de la membrana basal endotelial y por ende del endotelio. Incluso se ha visto que adicional a esto la homocisteinilación de la enzima lisil-oxidasa (LOX) clave en el proceso de lisil-oxidación del colágeno para entrecruzamiento, es un factor que vulnera doblemente en este punto.

- Se ha incluso determinado la homocisteinilación de la PON1 y de la apolipoproteína A1 de las HDL, vulnerando así la actividad barredora de HCTL y el rol antiinflamatorio de las HDL.

- La HCTL daña en modelos experimentales el señalamiento dependiente de la insulina, que es reversado con glutatión. 2,3, 52,53,54

Incluso este daño endotelial generado por hiperhomocistinemia vulnera la del endotelio cavernoso generando disfunción erectil, efecto mediado tanto por radicales libres como por depleción de NADPH..$^{98}$

\section{La hiperhomocistinemia y la ADMA}

La HipHomCis se relaciona con elevadas concentraciones de ADMA en animales y humanos, pero no está clara la asociación aún. La ADMA al igual que la HipHomCis son toxinas urémicas. La di-metil-arginina asimétrica (ADMA) es el inhibidor endógeno por excelencia de las óxido nítrico-sintetasas (NOS), originalmente descrita como una toxina urémica, la cual compite con la L-arginina, con su sitio unidor y en consecuencia hace la inhibición enzimática. Se produce mediante la metilación del nitrógeno guanidino de las argininas estructurales proteicas por medio de las enzimas proteína-argininametiltransferasas (PRMT), para lo cual es necesario el cofactor SAM, y después se libera por proteolisis. Al principio se genera el intermediario mono-metil (LNMMA). Las PRMT se clasifican en dos grandes grupos, las del tipo I (PRMT1, PRMT3, PRMT4 y PRMT6) que sintetizan la molécula asimétrica (ADMA), y las del tipo II (PRMT5 y PRMT7) que sintetizan la molécula simétrica (SMDA). Las transferasas PRMT2, PRMT8 y PRMT9 no se han clasificado aún en forma adecuada. Las proteínas arginina-metiladas tienen una alta tasa de recambio.

La metilación irreversible de la arginina como tal es un proceso de gran esencia biológica que regula procesos como la transcripción génica, la traducción génica y el corte y empalme alternativo del ARN mensajero 
(splicing). Así mismo, la metilación de la arginina es un mecanismo protector contra las modificaciones por dicarbonilos reactivos como el metil-glioxal (MG), que es una molécula producto colateral de la glicólisis y otras vías metabólicas con actividad citotóxica, que modifica proteínas y ácidos nucleicos, y el cual de manera natural se neutraliza mediante la detoxificación catalizada por el sistema enzimático glioxalasa y el de las carbonilreductasas. La arginina natural y el intermediario monometil-arginina proteica son blanco entre otras reacciones de la deiminación por las enzimas PAD (proteína-arginina-deiminasas), como una modificación postraduccional normal que fuera de ser un mecanismo regulador de la función proteica logra en forma favorable por competición de sustrato inhibir la modificación por MG hacia productos de glicosilación avanzada, AGE. Como es irreversible, es evidente que sólo se neutraliza por proteólisis.

La ADMA tiene su propio ciclo metabólico. Las di-metilarginina-dimetil-amino-hidrolasas (DDAH) son enzimas citosólicas que catabolizan por hidrólisis la ADMAy así regulan su concentración. Por medio de mecanismos aún no claros, la DDAH2 puede regular de manera negativa la secreción de su sustrato ADMA e incrementar la expresión de VEGFA/VPF (factor de crecimiento vascular endotelial isoforma $\mathrm{A} /$ factor de permeabilidad vascular). No toda la ADMA es degradada y escapa a partir de las células a través de transportadores para aminoácidos catiónicos, los cuales también están implicados en la captación por otras células o en la recaptación por parte de la misma célula que lo produce. La ADMA se elimina por riñón e hígado y, en parte, puede excretarse por vía urinaria. Tanto las PRMT como las DDAH son reguladas por estrés de oxidorreducción.

Es probable que exista homocisteinilación de las DDAH, lo cual las inhibe y por ende se suben los niveles de ADMA. La s-nitroso-homocisteína también puede inhibir en forma potente las DDAH, lo cual permite identificar otro mecanismo a través del cual la HipHomCis incrementa los niveles de ADMA. Éstos constituyen un predictor independiente de enfermedad cardiovascular, sus niveles están elevados en insuficiencia renal, afecciones cardiovasculares (enfermedad hipertensiva incluyendo las variantes gestacionales, diabetes, aterosclerosis,HipHomCis) y en el síndrome metabólico
$\mathrm{X}$ (de Reaven), de tal forma que aparece como un nuevo marcador de riesgo en este campo, pero su valor pronóstico permanece sin definirse..$^{99,100}$

\section{Hiperhomocistinemia y defectos del tubo neural}

La alta incidencia de espina bífida es un rasgo particular de los defectos del metabolismo de la HomCis. La relación entre ácido fólico y defectos congénitos es clara y por ello se recomienda la suplementación gestacional de esta vitamina para proteger contra ciertos defectos del tubo neural y otros como las anomalías de la septación cardíaca conotruncales y orofaciales. Hoy se considera la HipHomCis per se teratogénica. El grupo de Rosenquist en 1996 con embriones aviares demostró por primera vez en forma satisfactoria la teratogenicidad de la HipHomCis. La neuroteratogenicidad de la HomCis parece ser causada por su rol como antagonista del neurotransmisor glutamato, actuando como un antagonista competitivo del Glu-R-NMDA, uniéndose al sitio coagonista de la glicina. ${ }^{55,101,102}$

\section{Hiperhomocistinemia y gestación}

MG Wouters y su grupo fueron los primeros que en 1993 observaron la asociación de HipHomCis con síndrome de pérdida gestacional recurrente. Este efecto deletéreo se ha informado en diversos estudios y se magnifica cuando hay niveles séricos bajos de folato. Varios estudios muestran también que el estrés endotelial producido por la HipHomCis podría explicar algunos eventos en la preeclampsia. Fuera de ello la HipHomCis como ya lo habíamos visto, es un inductor de trombofilia y en un estado trombofílico per se como la gestación, se duplica el riesgo de trombosis. ${ }^{9,10,103}$

\section{Hiperhomocistinemia y neoplasia}

Varios tipos de células cancerosas presentan una elevada dependencia de la MET y se está estudiando esta debilidad con fines quimioterapéticos. Por otro lado la 
HipHomCis se ha asociado con varios cánceres pero la evidencia es aún lo suficientemente fuerte. En varias líneas celulares se ha encontrado que su efecto potencial neoplasiogénico es por la inducción del factor de transcripción AP1, complejo formado por la asociación de miembros de la familia de factores de transcripción Jun y de la familia Fos. Un hallazgo interesante es la inducción del inhibidor de proteasa TIMP1, lo cual llevaría a que se altere la dinámica de la matriz extracelular en tejidos normales, cicatrización, regeneración y en cáncer. La HipHomCis desempeñaría un rol tanto en la génesis como en la historia natural del hepatocarcinoma, las leucemias, el cáncer colorrectal y el de mama. 63,64,72,95,104-108 Una alternativa para tratar la HipHomCis ligada a neoplasiogénesis es el potencial antioncógeno del ácido dehidro-ascórbico. ${ }^{109}$

\section{Hiperhomocistinemia y neurodesórdenes}

Esto permanece controversial pues hay estudios que asocian la HipHomCis con neurodegeneración, demencia senil, Alzheimer y Parkinson, pero otros reportes demuestran que no. Un punto común es que se ha encontrado una regulación por parte de la HomCis de la neurotransmisión glutamatérgica. ${ }^{4,110,111,112}$ Se podría anticipar que el daño endotelial de la vasculatura cerebral sería clave y que es lo denominado como demencia vascular primaria o añadida. ${ }^{113,114}$ También puede ser un evento clave en el riesgo de demencia en el climaterio y la menopausia. ${ }^{115}$

\section{Hiperhomocistinemia y tejidos conectivos: autoinmunidad $y$ osteoporosis}

Diversos tipos de alteraciones se pueden producir la HipHomCis en forma secundaria, alterando tanto la biosíntesis como la estructura de los tejidos conectivos. Un evento interesante es la alteración de la fibrilarina 1. Sin embargo, parece real la generación de neoantígenos tanto como evento primario o secundario en la autoinmunidad sistémica del tipo del reumatismo. Por otro lado, como evento secundario la HipHomCis es un fac- tor proaterosclerótico y de riesgo vascular en personas con enfermedades autoinmunes sistémicas. ${ }^{116-120}$ Puede ser el nexo real entre la osteoporosis y la aterosclerosis, en especial con el aumento de la edad. ${ }^{121,122}$

\section{Hiperhomocistinemia y envejecimiento}

La HipHomCis parece ser un hallazgo usual en el envejecimiento humano y las enfermedades asociadas. $\mathrm{La}$ menopausia parece aumentar aún más la HipHomCis. Estudios en varias especies incluyendo la humana han encontrado que la disminución de la HipHomCis incluso sólo por métodos dietarios retardan los eventos y las enfermedades propias de la senectud. ${ }^{123,124,125}$ Parece que la HipHomCis condiciona la autoinflamación y la proinflamación, en parte por la polarización Th1 de la respuesta celular específica. ${ }^{126}$

\section{Conclusiones}

Es evidente el rol de laHipHomCis en enfermedad humana. Se ha encontrado que es una verdadera toxina que por múltiples rutas puede ser el evento primario desencadenante o un factor secundario en escenarios clínicos que son frecuentes como el síndrome metabólico y sus entidades relacionadas, en cáncer y en diversos trastornos neuropsiquiátricos. La HipHomCis puede ser un estandarte en otras entidades como el hipotiroidismo ${ }^{127,128}$ y explicar el mayor riesgo cardiovascular en escenarios como el tabaquismo, ${ }^{129,130}$ la alta ingesta de café (cafeína y otras metilxantinas) ${ }^{131}$, los andrógenos en el sexo masculino y la terapia con estas hormonas ${ }^{132,133}$, la administración de ciertos fármacos hipolipemiantes como ácido nicotínico y fibratos ${ }^{134}$, y el uso de hipoglicemiantes orales como la metformina. ${ }^{135}$ Ciertos antihipertensivos/ hipotensores tienen efectos contrarios, así los diuréticos causan HipHomCis mientras los betabloqueadores y los inhibidores de la enzima convertidora de angiotensina son hipohomocisteinantes. ${ }^{136}$ De ahí que la farmacoterapia de este trastorno sea un área interesante para emplear diversas herramientas como la dieta y la suplementación con barredores de HomCis como la colina, la betaína y la creatina. ${ }^{137}$ 


\section{Potencial conflicto de interés}

\section{El autor manifiesta que no existe ningún conflicto de in- terés en lo expuesto en este escrito académico.}

\section{Referencias}

1. Ramakrishnan S, Sulochana KN, Lakshmi S et al. Biochemistry of homocysteine in health and diseases. Indian J Biochem Biophys. 2006; $43: 275-83$

2. Huang T, Yuan G, Zhang $Z$ et al. Cardiovascular pathogenesis in hyperhomocysteinemia. Asia Pac J Clin Nutr. 2008;17:8-16

3. Trabetti E. Homocysteine, MTHFR gene polymorphisms, and cardio-cerebrovascular risk. J Appl Genet. 2008;49:267-82

4. Obeid R, McCaddon A, Herrmann W. The role of hyperhomocysteinemia and B-vitamin deficiency in neurological and psychiatric diseases. Clin Chem Lab Med. 2007:45:1590-606

5. Deth R, Muratore C, Benzecry J et al. How environmental and genetic factors combine to cause autism: A redox/methylation hypothesis. Neurotoxicology. 2008;29:190-201.

6. Frankenburg FR. The role of one-carbon metabolism in schizophrenia and depression. Harv Rev Psychiatry. 2007; 15:146-60

7. Folstein M, Liu T, Peter I, Buell J et al. The homocysteine hypothesis of depression. Am J Psychiatry. 2007; 164:861-7

8. Almeida OP, McCaul K, Hankey GJ et al. Homocysteine and depression in later life. Arch Gen Psychiatry. 2008;65:1286-94.

9. Dodds L, Fell DB, Dooley KC et al. Effect of homocysteine concentration in early pregnancy on gestational hypertensive disorders and other pregnancy outcomes. Clin Chem. 2008;54:326-34

10. Forges $\mathrm{T}$, Pellanda $\mathrm{H}$, Diligent $\mathrm{C}$ et al. Do folates have an impact on fertility? Gynecol Obstet Fertil. 2008;36:930-9.

11. Devlin TM. Textbook of Biochemistry with Clinical Correlations, 6a. ed., New York. Wiley-Liss. 2006

12. Nelson DL, Cox MM. Lehninger Principles of Biochemistry, 5a. ed., New York. W. H. Freeman. 2008

13. Berg JM, Tymoczko JL, Stryer L. Biochemistry, 6a. ed., New York. W. H Freeman. 2006

14. Scriver CR, Sly WS, Childs B, et al. The metabolic and molecular basis of inherited disease, 8a. ed., New York. McGraw-Hill Professional. 2001

15. OMIM [base de datos en Internet]. Baltimore: Johns Hopkins University; 1966- [fecha de acceso 15 de agosto del 2009]. Disponible en: http:// www.ncbi.nlm.nih.gov/entrez/dispomim

16. HUGO [base de datos en Internet]. Bethesda: National Library of Medicine and others(exp.: Celera Genomics and the Sanger Center); 1989- [fecha de acceso 15 de agosto del 2009]. Disponible en: http://www.hugointernational.org/index.html

17. IUMBM[base de datos en Internet]. London: International Union of Biochemistry and Molecular Biology; 1977- [fecha de acceso 15 de agosto del 2009]. Disponible en: http://www.chem.qmul.ac.uk/iupac/jcbn/index.html\#2

18. PubMed [base de datos en Internet]. Bethesda: National Library of Medicine; 1966- [fecha de acceso 15 de agosto del 2009]. Disponible en: http:// www.ncbi.nlm.nih.gov/PubMed/

19. EMBASE [base de datos en Internet]. Holanda: Excerpta Medica-Elsevier 1974-[fecha de acceso 15 de agosto del 2009]. Disponible en: http:// www embase com

20. Steensholt G. On the methylation of ethanol amine, dimethyl ethanol amine, guanidine acetic acid and homocysteine. Acta Physiol Scand. 1947;14:340-7.
21. Greenberg DM. Biological methylation. Adv Enzymol Relat Areas Mol Biol. 1963;25:395-431

22. Pasieka AE, Morgan JF. The detection of homocysteine in biological systems Biochim Biophys Acta. 1955;18:236-40.

23. Bartosinski B. Biosynthesis of methyl group of methionine. Postepy Biochem. 1964;10:463-74.

24. Langemann $\mathrm{H}$, Kensler CJ. Spontaneous increase in the rate of formation of methionine from dimethylthetin and homocysteine in rat liver homogenates. Arch Biochem. 1951;33:344-5.

25. Gibson F, Woods DD. The synthesis of methionine from homocysteine by Escherichia coli. Biochem J. 1952;51(1):v.

26. Eger W. Cysteine, homocysteine, cystathionine \& cysteinamine as necrotropic liver protective substances, combined with glucose \& fructose. Medizinische. 1957; 17:618-23.

27. Trutschel W. Homocysteine-thiolactone, cysteine and fructose therapy of acute and chronic hepatitis. Arztl Wochensch. 1957;12:541-5.

28. Frimpter GW. The disulfide of L-cysteine and L-homocysteine in urine of patients with cystinuria. J Biol Chem. 1961;236:PC51-3.

29. Freycon F, Freycon MT. Homocystinuria. Pediatrie. 1965;20:495-7.

30. Chatagner F. Biochemical aspects of some congenital anomalies of the metabolism of sulfur amino acids. Expos Annu Biochim Med. 1967;28:53-76.

31. Crawhall JC, Watts RW. Cystinuria. Am J Med. 1968;45:736-55.

32. No autores listados. Defective vitamin B 12 metabolism in the human being: changes in methionine and methylmalonic acid excretion. Nutr Rev. 1969:27:202-4

33. Hogenkamp HP. Enzymatic reactions involving corrinoids. Annu Rev Biochem. 1968;37:225-45.

34. Bertino JR, Hillcoat BL. Regulation of dihydrofolate reductase and other folate-requiring enzymes. Adv Enzyme Regul. 1968;6:335-49.

35. Sakami W, Stevens A. Synthesis and properties of adenosyl-L-homocysteine Bull Soc Chim Biol (Paris). 1958;40:1787-93

36. Lombardini JB, Talalay P. Formation, functions and regulatory importance of S-adenosyl-L-methionine. Adv Enzyme Regul. 1970;9:349-84

37. Weissbach $\mathrm{H}$, Taylor RT. Roles of vitamin B 12 and folic acid in methionine synthesis. Vitam Horm. 1970;28:415-40.

38. Mahoney MJ, Rosenberg LE. Inherited defects of B12 metabolism. Am J Med. 1970;48:584-93.

39. Waxman S, Corcino JJ, Herbert V. Drugs, toxins and dietary amino acids affecting vitamin B12 or folic acid absorption or utilization. Am J Med. 1970:48:599-608

40. Hoffbrand AV, Waters AH. Observations on the biochemical basis of megaloblastic anaemia. Br J Haematol. 1972;23:Suppl:109-18

41. Brosnan JT, Brosnan ME. The sulfur-containing amino acids: an overview J Nutr. 2006;136(6 Suppl):1636S-1640S.

42. Pajares MA, Pérez-Sala D. Betaine homocysteine S-methyltransferase: just a regulator of homocysteine metabolism? Cell Mol Life Sci. 2006;63:2792-803.

43. Yamanishi $\mathrm{M}, \mathrm{Kabil} \mathrm{O}$, Sen $\mathrm{S}$ et al. Structural insights into pathogenic mutations in heme-dependent cystathionine-beta-synthase. J Inorg Biochem. 2006; 100:1988-95

44. Brosnan JT, da Silva R, Brosnan ME. Amino acids and the regulation of methyl balance in humans. Curr Opin Clin Nutr Metab Care. 2007;10:52-7.

45. Burrin DG, Stoll B. Emerging aspects of gut sulfur amino acid metabolism

Curr Opin Clin Nutr Metab Care. 2007;10:63-8.

46. Markham GD, Pajares MA. Structure-function relationships in methionine adenosyltransferases. Cell Mol Life Sci. 2009;66:636-48

47. Loenen WA. S-adenosylmethionine: jack of all trades and master of everything? Biochem Soc Trans. 2006;34(Pt 2):330-3 
48. Roje S. S-Adenosyl-L-methionine: beyond the universal methyl group donor. Phytochemistry. 2006;67:1686-98.

49. Finkelstein JD. Metabolic regulatory properties of S-adenosylmethionine and S-adenosylhomocysteine. Clin Chem Lab Med. 2007;45:1694-9.

50. Grillo MA, Colombatto S. S-adenosylmethionine and its products. Amino Acids. 2008;34:187-93

51. Matthews RG, Elmore CL. Defects in homocysteine metabolism: diversity among hyperhomocyst(e)inemias. Clin Chem Lab Med. 2007;45:1700-3

52. Zhou J,Austin RC. Contributions of hyperhomocysteinemia to atherosclerosis: Causal relationship and potential mechanisms. Biofactors. 2009;35:120-9.

53. Hopoleanu C, Porojan-Iuga M, Rusu ML et al. Hyperhomocysteinemia clinical and therapeutical involvement in venous thrombosis. Rom J Intern Med. 2007;45:159-64.

54. Poredos P, Jezovnik MK. The role of inflammation in venous thromboembolism and the link between arterial and venous thrombosis. Int Angiol. 2007;26:306-11

55. Chen CP. Syndromes, disorders and maternal risk factors associated with neural tube defects (IV). Taiwan J Obstet Gynecol. 2008;47:141-50.

56. Martínez-Frías ML. The biochemical structure and function of methylenetetrahydrofolate reductase provide the rationale to interpret the epidemiological results on the risk for infants with Down syndrome. Am J Med Genet A. 2008;146A:1477-82.

57. Rachidi M, Lopes C. Mental retardation and associated neurological dysfunctions in Down syndrome: a consequence of dysregulation in critical chromosome 21 genes and associated molecular pathways. Eur J Paediatr Neurol. 2008; 12:168-82.

58. Ifergan I,AssarafYG. Molecular mechanisms of adaptation to folate deficiency. Vitam Horm. 2008;79:99-143.

59. McLean E, de Benoist B,Allen LH. Review of the magnitude of folate and vitamin B12 deficiencies worldwide. Food Nutr Bull. 2008;29(2 Suppl):S38-51

60. Neves C, Jorge R, Barcelos A. The network of methotrexate toxicity. Acta Reumatol Port. 2009;34:11-34

61. Romanelli P, Bouzari N. New clinical syndromes in dermatology. Semin Cutan Med Surg. 2006;25:79-86.

62. Gisondi P, Fantuzzi F, Malerba $\mathrm{M}$ et al. Folic acid in general medicine and dermatology. J Dermatolog Treat. 2007;18:138-46.

64. Oeffinger KC. Are survivors of acute lymphoblastic leukemia (ALL) at increased risk of cardiovascular disease? Pediatr Blood Cancer. 2008;50(2 Suppl):462-7.

65. Mato JM, Martínez-Chantar ML, Lu SC. Methionine metabolism and liver disease. Annu Rev Nutr. 2008;28:273-93.

66. Wijekoon EP, Brosnan ME, Brosnan JT. Homocysteine metabolism in diabetes. Biochem Soc Trans. 2007;35(Pt 5):1175-9.

67. Urquhart BL, House AA. Assessing plasma total homocysteine in patients with end-stage renal disease. Perit Dial Int. 2007;27:476-88.

68. Yi F, Li PL. Mechanisms of homocysteine-induced glomerular injury and sclerosis. Am J Nephrol. 2008;28:254-64.

69. Jamaluddin MS, Yang X, Wang H. Hyperhomocysteinemia, DNA methylation and vascular disease. Clin Chem Lab Med. 2007;45:1660-6.

70. Smith BC, Denu JM. Chemical mechanisms of histone lysine and arginine modifications. Biochim Biophys Acta. 2009;1789:45-57.

71. Svedruziæ ZM. Mammalian cytosine DNA methyltransferase Dnmt1 enzymatic mechanism, novel mechanism-based inhibitors, and RNA-directed DNA methylation. Curr Med Chem. 2008;15:92-106.

72. Thorne JL, Campbell MJ, Turner BM. Transcription factors, chromatin and cancer. Int J Biochem Cell Biol. 2009;41:164-75.

73. McPherson RA, Pincus MR. Henry's Clinical Diagnosis and Management by Laboratory Methods, 21a.ed., China. Saunders-Elsevier. 2007.
74. Selhub J. Public health significance of elevated homocysteine. Food Nutr Bull. 2008;29(2 Suppl):S116-25.

75. Glushchenko AV, Jacobsen DW. Molecular targeting of proteins by Lhomocysteine: mechanistic implications for vascular disease. Antioxid Redox Signal. 2007;9:1883-98

76. Jakubowski H. The molecular basis of homocysteine thiolactone-mediated vascular disease. Clin Chem Lab Med. 2007;45:1704-16

77. Pera-Kaján J, Twardowski T, Jakubowski H. Mechanisms of homocysteine toxicity in humans. Amino Acids. 2007;32:561-72.

78. Perna AF, Acanfora F, Luciano MG et al. Plasma protein homocysteinylation in uremia. Clin Chem Lab Med. 2007;45:1678-82.

79. Rodríguez Esparragón F, Hernández Trujillo Y, Macías Reyes A et al. Concerning the significance of paraoxonase-1 and SR-B1 genes in atherosclerosis. Rev Esp Cardiol. 2006;59:154-64

80. van Himbergen TM, van Tits LJ, Roest M et al. The story of PON1: how an organophosphate-hydrolysing enzyme is becoming a player in cardiovascular medicine. Neth J Med. 2006;64:34-8.

81. Florentin M, Liberopoulos EN, Wierzbicki AS et al. Multiple actions of high-density lipoprotein. Curr Opin Cardiol. 2008;23:370-8

82. Parthasarathy S, Litvinov D, Selvarajan K et al. Lipid peroxidation and decomposition - conflicting roles in plaque vulnerability and stability. Biochim Biophys Acta. 2008;1781:221-31.

83. Seo D, Goldschmidt-Clermont P. The paraoxonase gene family and atherosclerosis. Curr Atheroscler Rep. 2009;11:182-7.

84. Karasawa K. Clinical aspects of plasma platelet-activating factoracetylhydrolase. Biochim Biophys Acta. 2006;1761:1359-72

85. Sudhir K. Lipoprotein-associated phospholipase A2, vascular inflammation and cardiovascular risk prediction. Vasc Health Risk Manag. 2006;2:153-6.

86. Garza CA, Montori VM, McConnell JP et al. Association between lipoproteinassociated phospholipase $\mathrm{A} 2$ and cardiovascular disease: a systematic review. Mayo Clin Proc. 2007;82:159-65.

87. García GA, Gaitán AA, GarcíaA et al. Aspectos biomédicos de las fosfolipasas A2 en la especie humana. Med UNAB. 2008;11:14-27.

88. Brosnan JT, Jacobs RL, Stead LM et al. Methylation demand: a key determinant of homocysteine metabolism. Acta Biochim Pol. $2004 \cdot 51: 405-13$

89. Stead LM, Jacobs RL, Brosnan ME et al. Methylation demand and homocysteine metabolism. Adv Enzyme Regul. 2004;44:321-33.

90. Kharbanda KK. Role of transmethylation reactions in alcoholic liver disease. World J Gastroenterol. 2007;13:4947-54

91. Mato JM, Lu SC. Role of S-adenosyl-L-methionine in liver health and injury. Hepatology. 2007;45:1306-12.

92. Purohit V, Abdelmalek MF, Barve S et al. Role of S-adenosylmethionine, folate, and betaine in the treatment of alcoholic liver disease: summary of a symposium. Am J Clin Nutr. 2007;86:14-24

93. Ji C. Dissection of endoplasmic reticulum stress signaling in alcoholic and non-alcoholic liver injury. J Gastroenterol Hepatol. 2008;23 Suppl 1:S1624

94. Lu SC, Mato JM. S-Adenosylmethionine in cell growth, apoptosis and liver cancer. J Gastroenterol Hepatol. 2008;23 Suppl 1:S73-7.

95. Bleich S, Hillemacher T. Homocysteine, alcoholism and its molecular networks. Pharmacopsychiatry. 2009;42 Suppl 1:S102-9

96. Lubos E, Loscalzo J, Handy DE. Homocysteine and glutathione peroxidase1. Antioxid Redox Signal. 2007;9:1923-40.

97. Heil SG, De Vriese AS, Kluijtmans LA et al. The role of hyperhomocysteinemia in nitric oxide (NO) and endothelium-derived hyperpolarizing factor (EDHF)mediated vasodilatation. Cell Mol Biol (Noisy-le-grand). 2004;50:911-6.

98. Jin L, Burnett AL. NADPH oxidase: recent evidence for its role in erectile dysfunction. Asian J Androl. 2008;10:6-13. 
99. Garcia GA, Clavijo DA, Mejía OR et al. Biología, patobiología, bioclínica y farmacoterapéutica de la di-metil-arginina asimétrica (ADMA) en la especie humana. Universitas Médica. 2006;47:335-48.

100. van Guldener C, Nanayakkara PW, Stehouwer CD. Homocysteine and asymmetric dimethylarginine (ADMA): biochemically linked but differently related to vascular disease in chronic kidney disease. Clin Chem Lab Med 2007;45:1683-7.

101. Beaudin AE, Stover PJ. Folate-mediated one-carbon metabolism and neural tube defects: balancing genome synthesis and gene expression. Birth Defects Res C Embryo Today. 2007;81:183-203.

102. Taparia S, Gelineau-van Waes J, Rosenquist TH etal. Importance of folatehomocysteine homeostasis during early embryonic development. Clin Chem Lab Med. 2007;45:1717-27.

103. Pabinger I. Thrombophilia and its impact on pregnancy. Thromb Res 2009;123(Suppl 3):S16-21

104. Selvakumar P, Lakshmikuttyamma A, Dimmock JR et al. Methionine aminopeptidase 2 and cancer. Biochim Biophys Acta. 2006;1765:148-54

105. Rosado JO, Salvador M, Bonatto D. Importance of the trans-sulfuration pathway in cancer prevention and promotion. Mol Cell Biochem. 2007;301:1-12

106. Beetstra S, Suthers G, Dhillon V et al. Methionine-dependence phenotype in the de novo pathway in BRCA1 and BRCA2 mutation carriers with and without breast cancer. Cancer Epidemiol Biomarkers Prev. 2008;17:2565-71

107. Durando X, Thivat E, Gimbergues $P$ et al. Methionine dependency of cancer cells: a new therapeutic approach? Bull Cancer. 2008;95:69-76.

108. Weinstein SJ, Albanes D, Selhub J et al. One-carbon metabolism biomarkers and risk of colon and rectal cancers. Cancer Epidemiol Biomarkers Prev. 2008; 17:3233-40.

109. Toohey JI. Dehydroascorbic acid as an anti-cancer agent. Cancer Lett 2008;263:164-9

110. Boldyrev AA, Johnson P. Homocysteine and its derivatives as possible modulators of neuronal and non-neuronal cell glutamate receptors in Alzheimer's disease. J Alzheimers Dis. 2007;11:219-28

111. Martignoni E, Tassorelli C, Nappi G et al. Homocysteine and Parkinson's disease: a dangerous liaison? J Neurol Sci. 2007;257:31-7.

112. Tchantchou F, Shea TB. Folate deprivation, the methionine cycle, and Alzheimer's disease. Vitam Horm. 2008;79:83-97

113. Mielke MM, Zandi PP. Hematologic risk factors of vascular disease and their relation to dementia. Dement Geriatr Cogn Disord. 2006;21:335-52

114. Román GC. Vascular dementia prevention: a risk factor analysis. Cerebrovasc Dis. 2005;20(Suppl 2):91-100

115. Shah S, Bell RJ, Davis SR. Homocysteine, estrogen and cognitive decline Climacteric. 2006;9:77-87

116. Whiteman P, Hutchinson S, Handford PA. Fibrillin-1 misfolding and disease Antioxid Redox Signal. 2006;8:338-46.

117. Lazzerini PE, Capecchi PL, Selvi E et al. Hyperhomocysteinemia: a cardiovascular risk factor in autoimmune diseases? Lupus. 2007; 16:852-62.

118. Lazzerini PE, Capecchi PL, Selvi E et al. Hyperhomocysteinemia, inflammation and autoimmunity. Autoimmun Rev. 2007;6:503-9.

119. SzekaneczZ, Kerekes G Dér H et al. Accelerated atherosclerosis in rheumatoid arthritis. Ann N Y Acad Sci. 2007;1108:349-58

120. Toohey JI. Homocysteine toxicity in connective tissue: theories, old and new. Connect Tissue Res. 2008;49:57-61

121. McLean RR, Hannan MT. B vitamins, homocysteine, and bone disease epidemiology and pathophysiology. Curr Osteoporos Rep. 2007;5:112-9
122. Anagnostis P, Karagiannis A, Kakafika AI et al. Atherosclerosis and osteoporosis: age-dependent degenerative processes or related entities? Osteoporos Int. 2009;20:197-207

123. Kuo HK, Sorond FA, Chen JH et al. The role of homocysteine in multisystem age-related problems: a systematic review. J Gerontol A Biol Sci Med Sci. 2005;60:1190-201.

124. Pamplona R, Barja G. Mitochondrial oxidative stress, aging and caloric restriction: the protein and methionine connection. Biochim Biophys Acta. 2006; 1757:496-508

125. Uthus EO, Brown-Borg HM. Methionine flux to transsulfuration is enhanced in the long living Ames dwarf mouse. Mech Ageing Dev. 2006;127:444-50.

126. Dai J, Wang X. Immunoregulatory effects of homocysteine on cardiovascular diseases. Sheng Li Xue Bao. 2007;59:585-92

127. Duntas LH, Wartofsky L. Cardiovascular risk and subclinical hypothyroidism focus on lipids and new emerging risk factors. What is the evidence? Thyroid. 2007; $17: 1075-84$

128. Mariotti S, Cambuli VM. Cardiovascular risk in elderly hypothyroid patients. Thyroid. 2007; 17:1067-73

129. Goldstein LB, Adams R, Alberts MJ et al. American Heart Association American Stroke Association Stroke Council. Primary prevention of ischemic stroke: a guideline from the American Heart Association/American Stroke Association Stroke Council: cosponsored by the Atherosclerotic Peripheral Vascular Disease Interdisciplinary Working Group; Cardiovascular Nursing Council; Clinical Cardiology Council; Nutrition, Physical Activity, and Metabolism Council; and the Quality of Care and Outcomes Research Interdisciplinary Working Group. Circulation. 2006;113:e873-923

130. Goldstein LB, Adams R, Alberts MJ et al. American Heart Association/ American Stroke Association Stroke Council; Atherosclerotic Peripheral Vascular Disease Interdisciplinary Working Group; Cardiovascular Nursing Council; Clinical Cardiology Council; Nutrition, Physical Activity, and Metabolism Council; Quality of Care and Outcomes Research Interdisciplinary Working Group; American Academy of Neurology. Primary prevention of ischemic stroke: a guideline from the American Heart Association/American Stroke Association Stroke Council: cosponsored by the Atherosclerotic Peripheral Vascular Disease Interdisciplinary Working Group; Cardiovascular Nursing Council; Clinical Cardiology Council; Nutrition, Physical Activity, and Metabolism Council; and the Quality of Care and Outcomes Research Interdisciplinary Working Group: the American Academy of Neurology affirms the value of this guideline. Stroke 2006;37:1583-633.

131. Higdon JV, Frei B. Coffee and health: a review of recent human research. Crit Rev Food Sci Nutr. 2006;46:101-23.

132. MueckAO, Seeger H. Biochemical markers surrogating on vascular effects of sex steroid hormones. Gynecol Endocrinol. 2006;22:163-73

133. Gooren LJ, Giltay EJ. Review of studies of androgen treatment of female-tomale transsexuals: effects and risks of administration of androgens to females. J Sex Med. 2008;5:765-76.

134. Thomas $\mathrm{C}$. Letter to the editor by X. Roblin et al., Influence of hypolipemic treatment on homocysteinemia] Rev Med Interne. 2003;24:335-6.

135. Musarrat K, Kalathil D, Varughese GI. Metformin, B12 and homocysteine levels: the plausible cause or effect? J Formos Med Assoc. 2008;107:505-6.

136. Poduri A, Kaur J, Thakur JS et al. Effect of ACE inhibitors and beta-blockers on homocysteine levels in essential hypertension. J Hum Hypertens. 2008;22:289-94.

137. Maron BA, Loscalzo J. The Treatment of Hyperhomocysteinemia. Annu Rev Med 2009:60:39-54 